\title{
MÉTODOS INDIRETOS PARA ESTIMATIVA DE MASSA DE FORRAGEM EM PASTAGENS DE Cynodon spp.
}

\section{WALDELIZA FERNANDES DA CUNHA}

Dissertação apresentada à Escola Superior de Agricultura "Luiz de Queiroz", Universidade de São Paulo, para obtenção do título de Mestre em Agronomia, Área de Concentração: Ciência Animal e Pastagens.

\author{
PIRACICABA \\ Estado de São Paulo - Brasil \\ Janeiro - 2002
}




\title{
MÉTODOS INDIRETOS PARA ESTIMATIVA DE MASSA DE FORRAGEM EM PASTAGENS DE Cynodon spp.
}

\author{
WALDELIZA FERNANDES DA CUNHA \\ ZOOTECNISTA
}

Orientador: Prof. Dr. Sila Carneiro da Silva

Dissertação apresentada à Escola Superior de Agricultura "Luiz de Queiroz", Universidade de São Paulo, para obtenção do título de Mestre em Agronomia, Área de Concentração: Ciência Animal e Pastagens.

PIRACICABA

Estado de São Paulo - Brasil

Janeiro-2002 
Dados Internacionais de Catalogação na Publicação (CIP)

DIVISÃO DE BIBLIOTECA E DOCUMENTAÇÃO - ESALQ/USP

Cunha, Waldeliza Femandes da

Métodosindiretos para estimativa de massa de forragem em pastagens de Cynodon spp. / Waldeliza Femandes da Cunha. - Piracicaba, 2002.

58 p. : il.

Dissertação (mestrado) - - Escola Superior de Agricultura Luiz de Queiroz, 2002.

Bibliografia.

1. Metodologia da pesquisa 2. Pastagens 3. Produção a nimal I. Título

CDD 636.08422

"Permitida a cópia total ou parcial deste documento, desde que citada a fonte - O autor" 
Aos meus familiares,

Meus pais, Walter e Leonilda, pelo apoio, incentivo em todos os momentos, pelo amor que me dedicaram e nos bons exemplos de vida que contribuíram no meu caráter e nos meus "valores".

Meus irmãos, Júnior e Wandréia, pelo amor, apoio, incentivo e companheirismo que sempre me dedicaram.

Aos meus sobrinhos, Laurinha, Heitor e Naara, por alegrarem minha vida, com um simples sorriso.

DEDICO

Aos meus amigos,

Patrícia Menezes dos Santos, Bobô, e ao Alexandre de Campos Gançalves, Buzão, pela participação ativa e direta nos ensinamentos científicos e de vida, fatores fundamentais para o passo gigantesco que tive no meu crescimento pessoal e profissional nesta fase da minha, que jamais esquecerei. 
"Um dia você aprende que...

...não importa em quantos pedaços seu coração foi partido, o mundo não pára para que você o conserte.

Aprende que o tempo não é algo que possa voltar para trás.

Portanto, plante seu jardim e decore sua alma, ao invés de esperar que alguém lhe traga flores,

E você aprende que pode suportar,

que realmente é forte e pode ir muito mais longe

depois de pensar que não se pode mais

E que realmente a vida tem valor e

que você tem valor diante da vida.

Nossas vidas são traidoras e

nos fazem perder o bem

que poderíamos conquistar

se não fosse o medo de tentar."

(William Shakespeare) 


\section{AGRADECIMENTOS}

À Deus, pela minha vida neste planeta, para tentar progredir espiritualmente.

Ao meu orientador Dr. Sila Carneiro da Silva pela confiança, compreensão e paciência, que muito contribuíram para minha evolução pessoal e profissional.

A todos os professores do Departamento de Produção Animal da ESALQ/USP, especialmente ao Prof ${ }^{o}$. Dr. Carlos Guilherme Silveira Pedreira, pelo incentivo e pelos preciosos ensinamentos dos conhecimentos transmitidos e à Prof ${ }^{\mathrm{a}}$ Ivanete Susin, responsável pelo setor de Ovinocultura, pela concessão dos animais utilizados no experimento, pelo carinho e incentivo durante o curso.

Ao Prof ${ }^{0}$ Moacyr Corsi e a doutoranda Patrícia Menezes dos Santos pela minha iniciação no universo da pesquisa.

Aos colegas de mestrado do GEPF, Alexandre de Campos Gonçalves, Daniel Sarmento, André Sbrissia e Adriano Lupinacci pelo incentivo, amizade, companheirismo e pela troca de experiências na convivência durante o trabalho.

Aos estagiários do GEPF, principalmente, ao Alexandre "Volvo" e a Érika "Kiçaça", pela dedicação, incentivo e amizade durante o nosso trabalho.

Aos amigos e companheiros de pós-graduação, especialmente, ao Henrique Rocha, Dimas, Rosane e André Souza, pela amizade, incentivo e pelo apoio essencial nos momentos mais difíceis na realização desse trabalho.

As minhas amigas de república Paulinha e Viviane pelo apoio, incentivo, paciência e tolerância durante todos os dias de convivência em nossa casa.

À amiga Estér pelo apoio, incentivo e direcionamento dos meus passos nos momentos difíceis. 
A secretária do Departamento de Produção Animal, Creide, e para a bibliotecária, Eliana, pela amizade e incentivo, desde a minha chegada na ESALQ.

A todos os funcionários do Departamento de Produção Animal pela cooperação e amizade.

Ao Sr. José Carlos Maschietto, pelo apoio e incentivo na minha iniciação da pós-graduação na ESALQ.

À CAPES, pela concessão da bolsa de estudo.

À FAPESP, pela concessão para a implantação da área experimental.

A todos que de alguma maneira contribuíram para a realização deste trabalho. 


\section{SUMÁRIO}

RESUMO

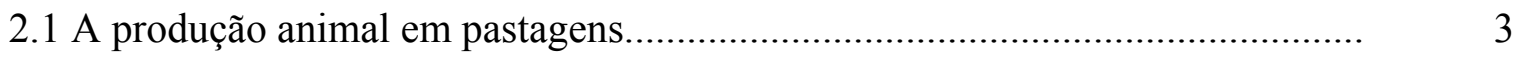

2.2 Métodos de avaliação ................................................................................

2.3 Métodos diretos para estimativas de massa de forragem.................................. 9

2.4 Métodos indiretos para estimativas de massa de forragem.............................. 12

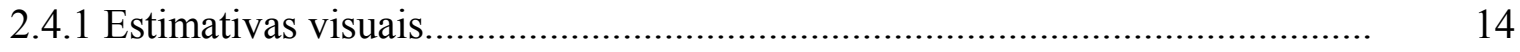

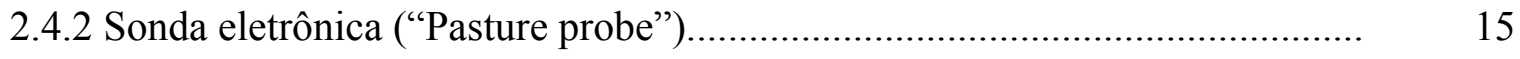

2.4.3 Altura comprimida (Altura e Densidade).................................................. 16

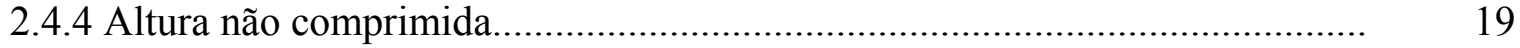

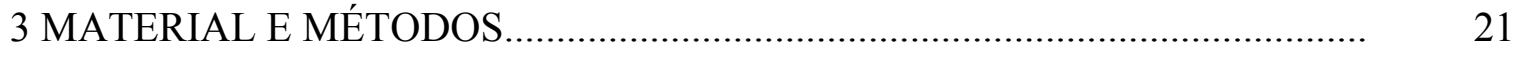

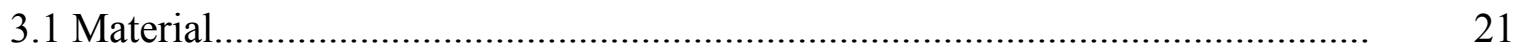

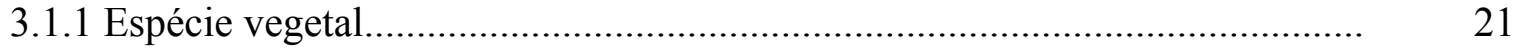

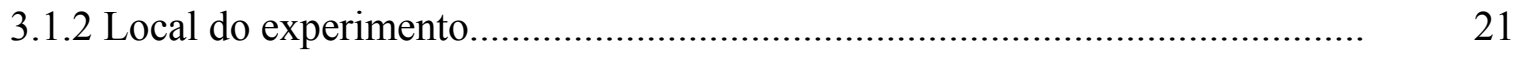

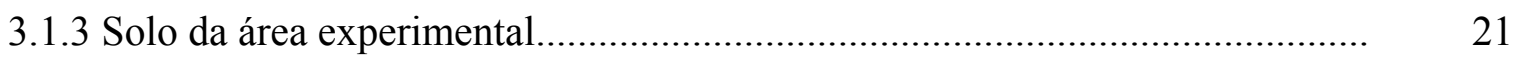

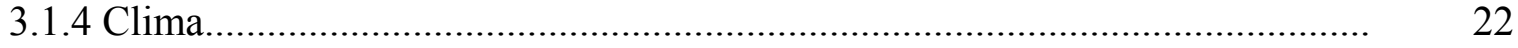

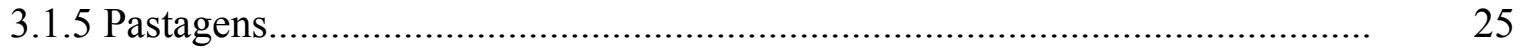

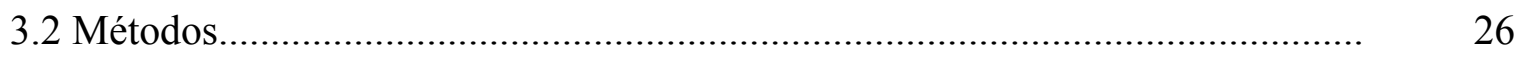

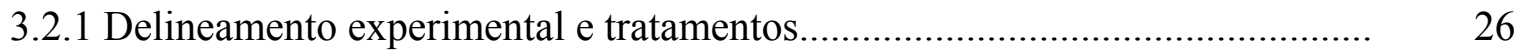


3.2.2 Instalações e monitoramento das condições experimentais.............................. 27

3.2.3 Calibração entre a altura comprimida e altura não comprimida...................... 28

3.3 Métodos utilizados para estimativa de massa de forragem............................. 29

3.4 Tratamento matemático dos dados e análise estatística.................................. 30

4 RESULTADOS E DISCUSSÃO .................................................................. 32

4.1 Análise dos dados para reconhecimento de possíveis padrões de

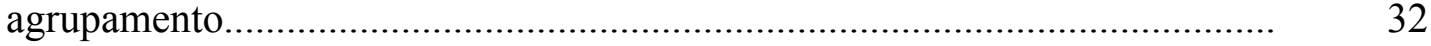

4.1.1 Método do prato ascendente ................................................................. 32

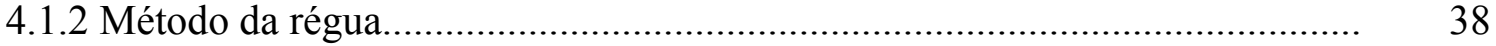

4.2 Equações de calibração dos métodos indiretos de estimativa de massa de forragem - prato ascendente e régua......

5 CONCLUSÕES.

REFERÊNCIAS BIBLIOGRÁFICAS........................................................ 50 


\title{
MÉTODOS INDIRETOS DE ESTIMATIVA DE MASSA DE FORRAGEM EM PASTAGENS DE Cynodon spp.
}

\author{
Autor: Waldeliza Fernandes da Cunha \\ Orientador: Prof. Dr. Sila Carneiro da Silva
}

\section{RESUMO}

O planejamento e o manejo do pastejo em sistemas de produção animal em pastagens utiliza como informação essencial valores de massa, produção e taxas de acúmulo de forragem. Esses valores podem ser determinados de maneira rápida e ágil através de uma simples régua graduada em centímetros ou equipamentos mais sofisticados como o prato ascendente, embora resultados experimentais utilizando esses procedimentos sejam bastante escassos para plantas de ambiente tropical. O presente trabalho avaliou esses dois métodos de estimativa de massa de forragem em área de pastagem formada pelos cultivares Florakirk, Tifton 85 e Coastcross de Cynodon spp.. Pastos formados por cada um dos cultivares foram mantidos a 5, 10, 15 e $20 \mathrm{~cm}$ de altura através de lotação contínua e taxa de lotação variável, seguindo um delineamento experimental de blocos completos ao acaso com 4 repetições. Durante 12 meses foram geradas curvas de calibração entre altura do pasto, medida por cada um dos dois métodos, e a massa de forragem correspondente. Como resultado foram geradas quatro curvas de calibração do tipo $\mathrm{y}=\mathrm{a}+\mathrm{bx}$ para cada cultivar $(\mathrm{y}=$ massa de forragem em $\mathrm{Kg}$ $\mathrm{MS} / \mathrm{ha}$ e $\mathrm{x}$ = altura do pasto), uma para cada época do ano (primavera, verão, outono e inverno). De forma geral os valores de intercepto (a) foram os mais influenciados por 
cultivar e época do ano, com uma variação apenas modesta nos valores de coeficiente angular (b). Essa variação esteve relacionada com modificações da estrutura do dossel dos pastos, particularmente a proporção de material morto. Os métodos não diferiram em precisão, porém o prato ascendente mostrou-se um método mais rápido e ágil. Concluiu-se que apesar das similaridades entre os cultivares estudados, a calibração dos métodos deve ser específica para cada cultivar e realizada frequentemente para que as equações geradas sejam precisas e robustas, de forma a permitir a obtenção de valores confiáveis de estimativas de massa de forragem. 


\title{
INDIRECT METHODS FOR ESTIMATES OF HERBAGE MASS IN Cynodon spp. SWARDS
}

\author{
Author: Waldeliza Fernandes da Cunha \\ Adviser: Prof. Dr. Sila Carneiro da Silva
}

\section{SUMMARY}

Grazing management and planning of animal production systems from pastures are essentially based on estimates of herbage mass, production and accumulation rates. These values can be rapidly determined with a sward stick and rising plate meter, although experimental results generated this way are scarce for tropical forage plants. The present experiment evaluated both methods for estimating herbage mass in pasture areas formed by Florakirk, Tifton 85 and Coastcross Cynodon spp. cultivars. Paddocks of each of the cultivars were maintained at 5,10,15 and $20 \mathrm{~cm}$ sward surface height through continuous stocking and variable stocking rate, according to a complete randomised block design with four replications. Over twelve months, calibration equations of stick and plate sward height versus the correspondent herbage mass were generated. As a result, four $\mathrm{y}=\mathrm{a}+\mathrm{bx}$ type calibration equations $(\mathrm{y}=$ herbage mass $-\mathrm{kg}$ $\mathrm{DM} / \mathrm{ha}$ and $\mathrm{x}=$ sward height) were obtained, one for each season of the year (spring, summer, autumn and winter). Generally, most of the variation among cultivars and seasons occurred in intercept values (a) and less with slope values (b). This variation was related to modifications in sward structure, particularly in dead material content. The methods did not differ in precision, although the rising plate meter proved to be faster and more agile. Despite the similarities among cultivars, calibration of both 
methods must be specific for each cultivar and carried out regularly in order to result in precise and robust equations capable of generating reliable estimates of herbage mass. 


\section{INTRODUÇÃO}

$\mathrm{Na}$ agricultura brasileira, a atividade pecuária é um dos setores mais importantes, uma vez que ocupa cerca de 185 milhões de hectares, gera milhares de empregos diretos e indiretos e tem uma participação significativa na renda bruta da agricultura nacional. As pastagens são a principal fonte de alimento para os animais domésticos, sendo cerca de $89 \%$ da criação de bovinos realizada exclusivamente em pastagens e o restante tendo utilizado áreas de pasto em alguma fase do processo de criação (FNP Consultoria \& Comécio, 2000).

A maioria das propriedades que pratica essa atividade, entretanto, tem índices de produtividade muito baixos e são caracterizadas por deficiências de manejo, dentre as quais ausência de monitoramento e controle da condição do pasto e produção de forragem nas áreas de pastagem. A estimativa e o monitoramento da variação da massa de forragem é uma das formas mais efetivas de gerar subsídios para os diversos processos de gerenciamento e tomada de decisão sobre o manejo do pastejo.

Várias são as técnicas disponíveis para estimar-se massa de forragem em áreas de pastagem, desde o corte de toda a forragem e sua pesagem, passando pelo corte de amostras em áreas de tamanho conhecido, até métodos indiretos, que relacionam outras características mais facilmente mensuráveis com a massa de forragem.

Essas técnicas, principalmente as indiretas, são bastante difundidas e utilizadas pelos produtores e pelos pesquisadores em países ditos de pecuária desenvolvida, tipicamente das regiões temperadas do globo, onde predominam pastagens formadas por plantas forrageiras de ciclo $\mathrm{C}_{3}$, principalmente do gênero Lolium. No entanto, no Brasil, a disponibilidade de dados e técnicas de campo para a realização desse tipo de estimativa de massa de forragem é ainda incipiente, o que é agravado pelo grande 
número de espécies de plantas forrageiras utilizadas em nossas áreas de pastagens e pela carência de informação sobre a ecofisiologia dessas plantas. O presente estudo avaliou dois métodos de estimativa de massa de forragem rotineiramente utilizados em áreas de pastagens de clima temperado com o objetivo de disponibilizar uma ferramenta útil para otimizar o uso de tempo, recursos e mão-de-obra, tanto em trabalhos de pesquisa como em avaliações de rotina em fazendas. Foram avaliados os métodos da régua e do prato ascendente durante um período de 12 meses em pastagens do gênero Cynodon, espécies Cynodon dactylon cv. Florakirk, Cynodon spp. cv. Tifton 85 e Cynodon spp. cv. Coastcross. 


\section{REVISÃO DE LITERATURA}

\subsection{A Produção Animal em Pastagens}

A produção de alimentos de origem animal a partir de herbívoros, animais que têm a habilidade de converter a energia captada pelas plantas no processo de fotossíntese e transformá-la em energia de mantença para a realização das funções vitais do seu metabolismo, é de grande importância para ajudar a humanidade a suprir as necessidades de proteína animal de sua dieta (Nabinger, 1996 e Maraschin, 1996).

A pastagem é a fonte de alimento mais barata para a produção de ruminantes, uma vez que é colhida pelo próprio animal, não demandando gastos com maquinário e nem com combustível para a sua colheita. O seu uso favorece a produção a custos baixos e, portanto, aumentando a competitividade da atividade relativamente a outras opções de exploração da terra (Da Silva \& Pedreira, 1997).

A Nova Zelândia é um dos principais exportadores de leite do mercado mundial e tem seu sistema de produção baseado no uso intensivo de pastagens. $\mathrm{O}$ baixo custo de produção confere àquele país uma grande flexibilidade para suportar as flutuações de preço do mercado internacional, principalmente redução dos preços. Contraditoriamente, em situações de aumento de preços, permite o incremento da produção por animal e da produtividade através do uso de suplementos concentrados e volumosos sem que isso comprometa a rentabilidade do sistema (Da Silva, 1997).

O Brasil possui uma vasta extensão territorial que abrange uma grande variabilidade edafoclimática, caracterizada por grande disponibilidade de fatores de crescimento e potencial para produção de forragem a partir de pastagens (Camargo, 1996). Países de clima temperado têm como base de suas pastagens plantas forrageiras 
de ciclo $\mathrm{C}_{3}$, cujo potencial de produção gira em torno de 18-20 toneladas de matéria seca por hectare (Da Silva, 1997). Plantas de ciclo $\mathrm{C}_{4}$, típicas de regiões tropicais e subtropicais, possuem potencial de produção muito superior, com produtividades de até 60-80 toneladas de MS/ha para capim elefante (Pennisetum purpureum, Schum) (Da Silva, 1997).

A realidade dos sistemas de produção em pastagens no Brasil revela, entretanto, o não aproveitamento do potencial produtivo existente, uma vez que uma filosofia extrativista é adotada pela maioria dos produtores, o que resulta em ineficientes índices zootécnicos como, por exemplo, uma taxa de lotação animal média de 0,85 U.A. por hectare, menos da metade daquela obtida em alguns países onde a exploração é baseada em plantas temperadas, com menor potencial produtivo em relação às plantas tropicais utilizadas no Brasil (Da Silva \& Sbrissia, 2000).

De acordo com Da Silva \& Pedreira (1996), sistemas de produção animal em pastagens são bastante complexos e requerem uma interação de conhecimentos multidisciplinares para que possam ser compreendidos de maneira efetiva. Por isso, é fundamental que se conheça o sistema de produção como um todo, seus componentes e suas características, além dos fatores que interferem na sua eficiência, para que seja possível a detecção dos pontos de estrangulamento para que estratégias objetivas e eficazes de manejo possam ser planejadas e adotadas.

Hodgson (1990) discutiu a produtividade animal em pastagens como sendo função de três estágios de produção: crescimento, utilização e conversão da forragem. Cada um desses estágios possui sua própria eficiência, a qual pode ser influenciada pelo manejo. É o conjunto de eficiências parciais que irá determinar o nível de produção a ser atingido por um determinado sistema.

Em sistemas de produção que visam explorar o mérito genético da planta forrageira, estimar a massa de forragem é imprescindível para o adequado planejamento da atividade, uma vez que a partir dessas estimativas pode-se estimar a taxa de acúmulo de matéria seca permitindo, assim, calcular-se a taxa de lotação e o desempenho animal através de ajustes na quantidade de forragem disponível. Adicionalmente, a quantificação correta fornece indicações constantes sobre a utilização da forragem 
produzida ou, então, a extensão do seu desperdício, fatores fundamentais na determinação da produtividade de sistemas agropecuários (Estrada et al., 1991).

$\mathrm{Na}$ região central do Brasil, o crescimento das pastagens ocorre de forma irregular ao longo do ano, de forma que cerca de 75 a $85 \%$ da produção total de forragem ocorre durante a época quente e chuvosa do ano, o "verão agrostológico". Essa concentração de produção, que na região sudeste do país vai de outubro a março, caracteriza a estacionalidade de produção das pastagens, fenômeno comum às plantas forrageiras tanto de clima temperado como tropical (Rolim, 1994). Essa estacionalidade de produção dificulta o planejamento da pecuária pela variabilidade da produção de matéria seca de estação para estação do ano e de mês para mês dentro de uma dada estação, tornando muito difícil o ajuste em taxas de lotação, época e quantidade a ser utilizada de suplementos e manejo do sistema de uma forma geral. Nesse cenário, a estimativa e o monitoramento das variações em massa de forragem adquirem um papel fundamental para a organização e racionalização do manejo do sistema.

Nesse contexto, técnicas eficientes e rápidas que permitam o monitoramento e estimativas rápidas e precisas de massa de forragem nas pastagens funcionam como ferramentas essenciais para o uso adequado dos recursos forrageiros existentes.

\subsection{Métodos de Avaliação de Massa de Forragem}

A maneira ideal para determinar-se a massa de forragem em uma pastagem seria a colheita de todo o material contido na área sendo avaliada. Entretanto, essa prática é inviabilizada pela quantidade de tempo gasto na realização do trabalho, pelo custo em mão-de-obra e equipamentos, e pelos danos a alimentação dos animais, já que sua fonte de alimento seria removida totalmente, e à própria pastagem, uma vez que novas amostragens na mesma área seriam inviabilizadas por determinado período de tempo.

Alternativamente, existem várias maneiras para se estimar massa de forragem em uma pastagem. Essas podem ser agrupadas em métodos diretos, baseados no corte de toda a forragem contida em uma área da pastagem sendo amostrada, e métodos indiretos, que não causam danos à pastagem e são normalmente mais ágeis, com menor demanda 
de mão-de-obra. Qualquer um dos métodos de avaliação deve representar de forma precisa as condições e/ou estado das pastagens, sem gerar quantidade excessiva de trabalho e mão-de-obra (Lopes et al., 2000, Frame, 1981 e Mannetje, 1987).

As estimativas para determinação de massa de forragem em uma pastagem são realizadas por amostragem. Uma das dificuldades para a utilização de procedimentos de amostragem está em determinar-se o número mínimo de amostras necessário para se incorporar toda a variabilidade existente na pastagem e, ao mesmo tempo, não remover quantidades excessivas de forragem e/ou exceder a capacidade de gerenciamento do trabalho de processamento das amostras (Shaw et al., 1987).

Segundo Mannetje (2000), outro aspecto que deve ser levado em consideração é se o procedimento de amostragem poderá ser utilizado com mais de um objetivo, pois além de dados quantitativos, pode-se requerer alguma forma de avaliação qualitativa, como composição botânica e/ou composição química da forragem, cobertura do solo, etc..

A variabilidade espacial em uma pastagem é, geralmente, muito grande, razão pela qual muito cuidado deve ser dispensado na escolha do tamanho, forma e número de áreas de amostragem a serem utilizadas. Normalmente, áreas maiores tendem a permitir uma coleta pontual onde a variabilidade na amostra seria menor. No entanto, o tamanho da amostra tenderia a ser compensado pelo menor número de pontos de amostragem geralmente utilizados nessa situação. Contrariamente, amostras de tamanho menor podem ter maior variabilidade, porém permitem que um maior número de amostras seja coletado, de forma que a área total da pastagem seja mais bem representada (Mannetje,1987). De uma forma geral, pastos uniformes, caracterizados por relvados homogêneos, permitem o uso de áreas de amostragem maiores, porém em menor número; já pastos menos uniformes necessitam de um compromisso ou equilíbrio maior entre tamanho mínimo da área de amostragem e número de amostras coletadas. Nessas situações, inclusive, áreas de amostragem de formato retangular seriam preferíveis àquelas de formato quadrado ou circular, uma vez que permitiriam incorporar uma maior proporção da variabilidade na área sendo amostrada (Mannetje,2000).

Além das repetições necessárias, cada amostra deve ser cortada com técnica e cautela, pois é fundamental a obtenção de dados confiáveis, principalmente se as 
avaliações forem realizadas em grandes extensões territoriais. Nesse sentido, o número de subamostras que deve compor uma amostra composta assume papel fundamental, pois permitirá o controle da variabilidade característica do espaço amostral sendo avaliado. Não é possível estabelecer-se "a priori” um número ótimo de amostras a ser coletado para os diferentes métodos, uma vez que esse número é dependente da variabilidade específica da área sendo avaliada, dos objetivos aos quais a avaliação se destina e do nível de precisão necessário na avaliação sendo realizada (Mannetje, 2000).

Existem grandes variações possíveis em áreas de pastagem, por isso não se encontra na literatura um guia com um número padrão de amostras a ser utilizado. Em casos de experimentação, é aconselhável realizar-se um estudo preliminar com o objetivo de gerar estimativas da variação entre tratamentos e entre subamostras dentro de tratamentos, para que se possa calcular o número de subamostras e amostras requeridos para um dado nível de precisão (Shaw et al.,1987).

Os locais selecionados para a retirada das amostras nas regiões de amostragem devem ser escolhidos aleatoriamente, respeitando-se os processos de casualização, uma vez que esse procedimento assegura a independência dos erros da avaliação (Mannetje,1987).

Em áreas de experimentação, para facilitar a escolha do local onde a amostra será coletada, recomenda-se utilizar a bordadura dos tratamentos para marcar e selecionar um par de coordenadas localizadoras dos pontos amostrados. Em áreas pequenas, o lado do "quadrado", ou qualquer outra forma de demarcar a área amostrada, pode ser utilizado como um dispositivo para localizar o ponto, enquanto que em áreas grandes os pontos amostrados são normalmente determinados através de caminhadas pela pastagem, com a ajuda de uma bússola para manter direção quando necessário, ou adotando-se rotas pré-determinadas de caminhamento. Para tanto, utilizam-se os cantos da área experimental como referência (Shaw et al.,1987).

Mannetje (2000) recomendou que antes do início de qualquer procedimento de amostragem deve ser realizada uma análise de custo-benefício, na qual se considere o tempo gasto para a realização do trabalho, o nível de precisão das avaliações, a demanda por mão-de-obra e recursos. Deve-se procurar um balanço ótimo entre essas variáveis para que o procedimento de amostragem seja o mais efetivo possível. Recomenda, ainda, 
que é necessário grande cuidado na escolha das variáveis a serem mensuradas e na utilização do método, uma vez que uma escolha inapropriada pode causar sérias limitações à interpretação dos resultados (Mannetje,1987).

Cóser et al. (1998) relataram que a caracterização da pastagem, dos recursos humanos e da infra-estrutura disponível é quem irá determinar o método de amostragem a ser utilizado para a estimativa da massa de forragem. No entanto, Mannetje (1987) e Shaw et al. (1987) relataram que muitos métodos estão disponíveis e que o pesquisador deve estar ciente de sua existência, sua aplicabilidade, e suas limitações para poder realizar a melhor escolha para o tipo particular de pastagem e do trabalho sendo realizado. Relacionaram, também, alguns critérios que devem ser levados em consideração para a escolha do método de avaliação para se estimar a massa de forragem em uma pastagem. Estes estariam relacionados com a uniformidade, densidade, altura, composição botânica da pastagem, forma de crescimento das espécies forrageiras predominantes, tamanho e forma da área experimental e/ou comercial, tempo necessário para a realização das avaliações, infra-estrutura e mão-de-obra disponíveis, precisão requerida, e as particularidades específicas da pastagem sendo avaliada. Por isso, métodos satisfatórios para pastagens densas, em áreas de maior fertilidade e localizadas em regiões úmidas podem não ser adequados para pastagens menos densas (abertas), localizadas em regiões áridas (Mannetje, 2000).

Segundo Mannetje (1987), a infra-estrutura exerce uma influência importante nas situações onde não existe equipamento motorizado para a colheita da forragem para amostragem, principalmente nos casos de grandes áreas a serem amostradas, situações em que métodos indiretos de avaliação adquirem uma importância relativa maior para o controle e monitoramento das áreas de pastagens.

A grande diversidade de espécies de plantas forrageiras e a enorme variabilidade dos ecossistemas onde se encontram, dificultam a escolha do método de avaliação a ser utilizado, sendo que as diferenças em características morfológicas e os diferentes teores de matéria seca das espécies que compõem o pasto são alguns dos principais fatores restritivos dos possíveis métodos de avaliação a serem empregados. Adicionalmente, em função das oscilações na produção de matéria seca de forragem durante o ano (estacionalidade), faz-se necessário que os métodos sejam adequados tanto 
para condições (épocas) de crescimento rápido como de crescimento lento das plantas forrageiras. Caso a amostragem não seja capaz de representar a variabilidade da pastagem, a quantidade de massa de forragem existente no local poderá ser sub ou super estimada (O’Rourke, 1984, Cóser et al., 1998 e Lopes et al., 2000).

\subsection{Métodos diretos para estimativas de massa de forragem}

Os métodos diretos de avaliação de massa de forragem baseiam-se no corte e remoção da forragem proveniente de uma área amostral ou da área total sendo avaliada. Assim, o método caracteriza-se como "destrutivo", uma vez que inviabiliza novas avaliações na área colhida da pastagem (Mannetje, 2000). Essa técnica é altamente exata e confiável desde que a alocação de tratamentos experimentais e/ou locais de amostragem sejam definidos de conformidade com processos de casualização e o número de amostras e subamostras esteja de acordo com os princípios e procedimentos estatísticos (Frame, 1987).

A amostragem direta é feita através do corte da forragem em uma determinada área, onde o material é recolhido e seco em estufa a $65^{\circ} \mathrm{C}$ por 72 horas, ou até atingir massa constante (Haydock \& Shaw, 1975). Vários são os equipamentos que podem ser utilizados para a colheita da forragem como, por exemplo, tesouras, facas, canivetes, foices e outros. Embora requeiram um maior esforço dos operadores de uma forma geral, são flexíveis quanto ao formato das áreas de amostragem onde podem ser operados, incluindo áreas retangulares, circulares, e, quadradas. As tesouras têm certa vantagem sobre os demais equipamentos manuais de corte, uma vez que permitem a separação do material cortado em componentes (e.g. caule/lâmina) ainda no campo, onde as plantas individuais são facilmente distinguíveis. Outra vantagem seria um maior controle e exatidão da altura de corte (Frame, 1987; Mannetje, 1987 e Mannetje, 2000).

A utilização de equipamentos mecanizados para aumentar o rendimento da amostragem resultou no desenvolvimento de máquinas especiais e na adaptação de outras já existentes. Estas englobam equipamentos normalmente utilizados para tosquia de ovinos, cortadores de grama, e colhedoras automotrizes, sendo estas as mais utilizadas em experimentos realizados em grandes áreas, em países onde a pesquisa em 
pastagem tem maior incentivo financeiro. No Brasil, os equipamentos de corte mais utilizados são as tesouras, canivetes, facas, tosquiadoras e roçadoras costais. A escolha do equipamento a ser utilizado, contudo, deve levar em consideração o tamanho das amostras a serem coletadas, o porte da planta forrageira, sua resistência e as condições de operação do equipamento. Geralmente as máquinas comerciais disponíveis requerem modificações para que resultados satisfatórios sejam obtidos na maioria dos procedimentos de amostragem, principalmente no Brasil, onde a maioria das plantas estudadas é de porte médio a alto e apresentam alta produção de biomassa. A maioria das máquinas disponíveis no mercado foi planejada para a colheita de plantas herbáceas, com alta proporção de folhas em relação a colmos e com pequenas produções de biomassa.

A proporção da área a ser amostrada pode variar de $100 \%$ a $10 \%$ no caso de áreas pequenas (parcelas), 5\% ou até menos no caso de áreas de avaliação muito extensas (Mannetje, 1987). Em experimentos onde as parcelas são colhidas integralmente, é aconselhável descartar a bordadura para eliminar efeitos de extremidades. Dessa maneira, pode-se colher uma porção central da parcela ou posições aleatórias. Guzman et al. (1992) concluíram que para plantas tropicais o tamanho ótimo da unidade amostral está entre 1 a $1,75 \mathrm{~m}^{2}$ no relevo plano e de 1,25 a 1,75 $\mathrm{m}^{2}$ no relevo inclinado.

A habilidade de controlar a altura que o material será cortado é uma exigência básica para todo equipamento que for utilizado para realizar a amostragem de massa de forragem de modo direto, pois as porções basais da planta forrageira poderão conter uma quantidade significativa de massa de forragem. Pelo fato dos equipamentos manuais serem os mais precisos no controle da altura de corte do material, estes seriam os mais recomendados, pois permitiriam o cálculo da massa de forragem residual com maior precisão. Outro aspecto que deve ser levado em consideração é a padronização da altura de corte no nível do solo com a finalidade de minimizar "erros", uma vez que se estabelece um referencial comum e consistente, independente de operador, planta forrageira e/ou tratamento. Um corte drástico, entretanto, pode danificar a planta e prejudicar sua rebrota caso os cortes sejam feitos de forma repetida na mesma área. Por isso, não devem ser realizadas amostragens periódicas no mesmo local em curtos 
intervalos de tempo, razão pela qual a área das parcelas passa a ser um fator limitante quando este método de avaliação de massa de forragem é empregado e outras avaliações precisam ser realizadas na mesma área.

O material coletado de pequenas áreas pode ser secado e pesado sem subamostragem. No entanto, quando a quantidade coletada de material for grande, este deverá ser pesado verde, homogeneizado e sub-amostrado para determinação do teor matéria seca, antes do cálculo de massa de forragem.

Amostras coletadas por equipamentos mecânicos, principalmente os que utilizam sucção como as ceifadoras, podem incorporar detritos, terra e esterco ao material coletado, contaminando a amostra. Isso poderá acarretar na superestimativa da quantidade e do teor de matéria seca, além de interferir nos resultados da análise química da forragem colhida.

Esse tipo de amostragem não é recomendado para áreas extensas de pastagens, pois geralmente apresenta erros grandes uma vez que uma pequena proporção da área é amostrada em função da inviabilidade do aumento do número de subamostras, geralmente necessário para representar adequadamente a grande variabilidade espacial na distribuição da massa de forragem existente na área. Além disso, requer grandes gastos em função da necessidade de mão-de-obra e equipamentos, o que faz com que a operação demande tempo e seja muito trabalhosa (Barnett,1974 e Mannetje, 1987).

Essas dificuldades podem levar o usuário a diminuir muito o número de amostras sendo coletado com o intuito de reduzir custos e necessidade de mão-de-obra, tornando a amostragem inadequada, o que resulta em baixa precisão e exatidão do método. Entretanto, se o número adequado de amostras for tomado, o problema será a "destruição" de parte da área do pasto pelo corte e remoção da forragem colhida, impossibilitando que essas áreas possam ser utilizadas para avaliações futuras em curto espaço de tempo. Assim, o dimensionamento das parcelas experimentais adquire grande importância no planejamento de experimentos em condições de campo (Barnett,1974). 


\subsection{Métodos indiretos para estimativas de massa de forragem}

Dadas as limitações de estimativas diretas de massa de forragem, foram desenvolvidas alternativas que visam tornar operacional o número de amostras sem, contudo, inviabilizar o processo de avaliação. São os chamados métodos indiretos, que são caracterizados pelo caráter "não destrutivo" da pastagem. Os métodos indiretos minimizam a remoção física da forragem e foram desenvolvidos, principalmente, em função da demanda por métodos rápidos que pudessem ser utilizados em áreas grandes de pastagens. Para tanto, algumas características desejáveis foram utilizadas como referência, a saber: a) redução da quantidade de trabalho e equipamentos, tempo e/ou recursos, com conseqüente redução do custo do processo de amostragem; b) possibilidade de utilização em áreas com animais em pastejo e/ou em locais de difícil acesso, onde não seria possível realizar a amostragem adequadamente utilizando-se o método direto; c) possibilidade de realização de amostragens em áreas pequenas, onde procedimentos destrutivos (diretos) poderiam afetar uma proporção relativamente grande da área da parcela e interferir com outras avaliações; d) permitir a classificação de tratamentos com grandes diferenças comparativas; e) promover um guia para estimar massa de forragem em sistemas de produção animal onde uma medida absoluta não fosse necessária (Frame, 1981).

Embora os métodos não-destrutivos (indiretos) sejam menos precisos quando comparados com os destrutivos (diretos), requerem menos tempo por observação e envolvem menor esforço físico por parte dos operadores. Assim, pode-se realizar um maior número de amostras por unidade de tempo relativamente ao método direto, otimizando o uso da mão-de-obra disponível e permitindo uma maior intensidade (número de amostras/área) de amostragem nos processos de monitoramento e avaliação de pastagens (Mannetje, 2000).

Os métodos indiretos são utilizados através da técnica de dupla-amostragem, isto é, dois métodos de avaliação, um direto e outro indireto, são utilizados de forma concomitante de maneira a gerar uma calibração do referencial indireto (estimativa 
visual, altura, capacitância, etc) a partir do direto. Após a calibração do método indireto escolhido, as estimativas de massa de forragem passam a ser feitas através das curvas de calibração geradas. Por essa razão é importante que a calibração seja feita de forma a abranger a amplitude de condições de pasto e massas de forragem onde o método indireto será utilizado (Frame,1981 e Mannetje,2000).

Gonzalez et al. (1990), trabalhando com capim-bermuda (Cynodon dactylon (L.) Pers.) com e sem a presença de animais, constaram que a massa de forragem calculada através de calibrações de altura da planta, disco medidor e da capacitância foi influenciada pela estrutura da pastagem. Em pastagens de Cynodon spp. cv. Coastcross, Carnevalli \& Da Silva (1999) relataram a necessidade de ajustar as curvas de calibração para manter a coerência e consistência da relação entre altura e massa de forragem de acordo com as épocas do ano e, conseqüentemente, as diferentes estruturas de pasto.

Dobashi et al. (2001), avaliando três métodos indiretos para determinação de massa de forragem de pastagens de capim Tanzânia irrigado, verificaram que todos os métodos apresentaram variações entre os ciclos de pastejo avaliados, indicando a necessidade de calibrações freqüentes.

Dessa forma, mesmo os métodos indiretos requerem o corte de algumas amostras, porém em menor número, e não necessariamente na área onde as avaliações serão realizadas. Todavia, o grande volume de dados e informação existentes sobre a utilização desses métodos é para pastagens de clima temperado. Como conseqüência, poucos são os técnicos e produtores que fazem uso dessa técnica no Brasil, sendo este um dos principais fatores que dificultam o planejamento e tomadas de decisão rápidas relativas ao manejo de sistemas de produção animal em pastagens.

Vários são os métodos indiretos existentes para estimar massa de forragem. Entre eles estão: a estimativa visual; a variação de capacitância entre a massa de forragem existente e um sensor eletrônico ("pasture probe" ou sonda eletrônica), altura comprimida do dossel utilizando-se o disco medidor (“disk meter") ou prato ascendente ("rising plate meter"), e a altura não comprimida do dossel, utilizando-se apenas uma régua graduada (Shaw et al., 1987). 


\subsubsection{Estimativas Visuais}

O princípio do método de estimativas visuais consiste na avaliação da massa de forragem presente em uma determinada área e sua comparação com uma referência visual anterior, o que permite a inferência sobre a massa de forragem existente na área.

Embora alguns observadores possam se tornar bastante habilidosos nessa técnica, esse procedimento não é muito objetivo, uma vez que variações sazonais na altura do pasto, densidade e teor de umidade da forragem podem influenciar as avaliações, limitando a exatidão da estimativa. Por outro lado, essa técnica permite que um grande número de avaliações seja realizado por unidade de área e/ou unidade experimental de forma rápida e ágil (Frame, 1981). No entanto, para sua utilização é necessário um treinamento prévio do observador, no qual a ele é apresentada uma série de condições de pasto caracterizadas por massas de forragem conhecidas (determinadas através do corte e pesagem), permitindo que seja desenvolvida uma escala visual de referência. Esse treinamento é importante, pois o observador deve ser capaz de relacionar o que visualiza com os padrões conhecidos para que possa inferir de forma segura sobre a quantidade de massa de forragem presente na área (Frame, 1981).

Assim, a eficácia do método é dependente do desenvolvimento da habilidade de julgamento e inferência orientados de um observador, habilidade essa que deve ser desenvolvida para cada tipo de pastagem em diferentes épocas do ano. A precisão da técnica pode ser melhorada com o aumento no número de padrões de referência no campo e com a experiência do observador (Frame, 1981).

Esse tipo de estimativa de massa de forragem poder ser utilizado como guia para a tomada de decisões técnicas, como uma avaliação preliminar de massa de forragem e para o monitoramento da velocidade de crescimento da pastagem (Tothill \& Partridge, citados por Mannetje, 2000 e Frame, 1981). No entanto, o seu uso em experimentação é limitado, uma vez que existe um grau elevado de subjetividade e variação dependente de observador (Frame, 1981). Thomson (1986) apontou que avaliações visuais feitas por observador bem treinado podem ser mais exatas e precisas que aquelas feitas pelo prato ascendente ou sonda eletrônica, uma vez que o observador é capaz de adaptar-se mais facilmente às variações em estrutura do dossel forrageiro. 


\subsubsection{Sonda Eletrônica ("Pasture probe”)}

A sonda eletrônica ou "pasture probe" baseia-se em mudanças de capacitância para estimar massa de forragem. A capacitância descreve a quantidade de carga elétrica armazenada por dois condutores separados por um isolador (Garcia Filho, 2001). A quantidade de capacitância é determinada pela área superficial dos condutores e pela resistência do isolador .

Uma sonda eletrônica é composta por uma haste que possui uma camada mais externa de material isolante, uma segunda, interna, formada por um tubo de alumínio e uma terceira, mais interna, que corresponde a um terra feito de aço inoxidável, cuja ponta projeta-se para fora da haste e serve para ser colocada em contato com o solo ou com o ar para realização das medições. Na extremidade oposta existe um medidor, que recebe o sinal emitido pelos condutores e gera uma leitura de capacitância (Mannetje, 2000). Na sonda, a ponta do terra e o tubo de alumínio correspondem aos dois condutores do capacitor e a camada externa da haste do aparelho ao isolador. O capacitor é parte de um circuito elétrico que gera um sinal de uma determinada freqüência. Mudanças em capacitância fazem com que a freqüência do sinal mude, e essa mudança é medida através da leitura do medidor do aparelho. Uma leitura com o aparelho com a ponta do terra no "ar" (distante do solo) fornece o nível de referência de capacitância a partir do qual as mudanças são marcadas quando o medidor é utilizado para medir forragem. A forragem tem uma capacitância maior que a do ar. Assim, quando a sonda é colocada no pasto e a ponta do terra na superfície do solo, a massa de forragem em torno da haste da sonda forma uma extensão do terra do aparelho, aumentando a área do condutor terra. Isso faz com que haja um aumento na leitura de capacitância medida pelo aparelho e esse valor pode ser relacionado com a quantidade de massa de massa de forragem existente no pasto (kgMS/ha) (Mannetje, 2000).

Existem no mercado diferentes tipos de sondas eletrônicas. Independentemente do modelo, esses aparelhos precisam ser calibrados antes de serem utilizados. A calibração consiste na tomada de uma série de amostras em condições de pasto caracterizadas por massas de forragem crescentes, cuja amplitude seja grande o 
suficiente para representar as condições de campo onde o equipamento será utilizado. Para tanto, identificados os locais de amostragem, aloca-se os delimitadores de área ("quadrado") para o corte da forragem mas, antes da colheita, realiza-se a leitura de capacitância da amostra. Tomada a leitura, a forragem é colhida, seca em estufa e pesada. Os dados pareados de capacitância e massa de forragem correspondente são submetidos a uma análise de regressão e uma equação de calibração gerada. Esta será utilizada para a realização das estimativas de massa de forragem subseqüentemente (Mannetje, 2000). O teor de água da forragem influência a leitura do aparelho, razão pela qual calibrações específicas são necessárias para plantas e épocas do ano e até mesmo para estádios de crescimento e horas do dia.

\subsubsection{Altura Comprimida (Altura e Densidade)}

A biomassa do dossel está relacionada com a altura e a densidade de forragem, mas medir plantas individuais acarreta dificuldades práticas, razão pela qual não é utilizado em qualquer tipo ou tamanho de pasto. No entanto, pode-se integrar medidas de altura e densidade da forragem de uma pastagem utilizando-se um equipamento denominado prato ascendente ou disco medidor (Mannetje, 2000). Este consiste, basicamente, de uma haste graduada em um disco metálico de massa e área conhecidas, normalmente feitos em alumínio, material leve e que confere sensibilidade às diferentes alturas e densidades do dossel forrageiro. A área do disco pode variar de 0,2 a $1 \mathrm{~m}^{2}$ (Frame, 1981).

O princípio do método baseia-se na correlação entre as leituras de altura realizadas pelo prato ascendente ou disco medidor e a massa de forragem correspondente. A avaliação de massa com o prato ascendente é feita introduzindo-se a ponta da haste no dossel de forma perpendicular, do topo para base, até o nível do solo. Durante esse percurso o prato é deslocado para cima e quando a haste atinge o solo fazse a leitura da posição do prato na escala da haste. Essa leitura é posteriormente transformada em massa de forragem através de equação de calibração apropriada e específica. No caso do disco medidor, a leitura é semelhante, porém o disco é mantido suspenso e, somente após a haste ter atingido o solo, é solto de forma a acomodar-se no 
topo do dossel. Nesse ponto onde o disco estaciona é tomada a leitura da altura. A transformação da leitura de altura em massa também é feita através de equação calibração apropriada e específica (Frame, 1981). A calibração deste método é semelhante àquela realizada para a capacitância, devendo-se ressaltar a necessidade de gerar tantas calibrações quantas forem necessárias a fim de que efeitos de épocas do ano, estádio de desenvolvimento das plantas e alterações morfológicas sejam contemplados pelas equações de calibração utilizadas (Aiken \& Bransby,1992; Bransby et al., 1977; Santillan et al., 1979).

Aiken \& Brabsby (1992), avaliando a variabilidade de observador para estimativas de massa de forragem com disco medidor, concluíram que o mesmo observador deve realizar todas as medidas do experimento. Entretanto, as variações entre os observadores podem ser minimizadas com o treinamento prévio dos mesmos.

Uma das grandes vantagens desse tipo de método indireto é a rapidez com que as amostragens são realizadas, permitindo que o operador faça cerca de 50 leituras em 15 minutos, incluindo anotações dos valores do indicador numérico da haste do equipamento. Em função do alto rendimento operacional desse método, mais "pontos" podem ser amostrados, permitindo uma maior abrangência e representatividade da variabilidade da pastagem (Frame, 1981).

O emprego de medidas não-destrutivas, como o prato ascendente, possibilita uma melhor avaliação do rendimento de áreas sob pastejo, reduzindo custos e trabalho, além de ser de fácil entendimento, adoção e utilização pelos produtores (Lopes et al., 2000 e Santillan et al., 1979).

No entanto, essa técnica de avaliação de massa de forragem é recomendada para espécies que têm hábito de crescimento prostado ou rasteiro, que apresentam folhas e hastes macias, como a maioria dos Cynodon. Em algumas estações do ano e para algumas espécies a presença de colmos grossos e alta proporção de inflorescências prejudica a precisão da calibração do disco (Frame, 1981 e Mannetje, 2000), como constatado por Carnevalli \& Da Silva (2000), quando do monitoramento das alturas de pasto com o auxílio do prato ascendente em pastagens de Cynodon spp. Foi observado que os colmos mantinham o prato numa posição mais elevada, acima do estrato de folhas, reduzindo a precisão das estimativas de massa de forragem. 
Em pastagens de crescimento cespitoso, onde touceiras são formadas, a pastagem pode apresentar grande quantidade de colmos rígidos, os quais podem interferir com as leituras do prato de forma que essas tenham uma baixa correlação com a massa de forragem (folhas) do dossel forrageiro (Gomes et al., 2000), pois, nesse caso, o prato responderia muito mais à altura do que à densidade.

Dobashi et al. (2001), avaliando os métodos indiretos do prato ascendente de alumínio, altura medida com a trena e do prato ascendente de madeira para a determinação e massa de forragem em pastagens de Panicum maximum cv. Tanzânia observaram que o método do prato ascendente de alumínio foi o mais preciso, obtendo os maiores coeficientes de determinação $(0,82)$ e os menores erros padrão de regressão (1549 $\mathrm{kg} \mathrm{MS} \mathrm{ha-1)} \mathrm{em} \mathrm{comparação} \mathrm{com} \mathrm{a} \mathrm{trena}\left(0,70\right.$ e $\left.2009 \mathrm{~kg} \mathrm{MS} \mathrm{ha}^{-1}\right)$ e prato ascendente de madeira (0,71 e $\left.1982 \mathrm{~kg} \mathrm{MS} \mathrm{ha}^{-1}\right)$, respectivamente. Entretanto, não se pode afirmar que este método seria o mais indicado para a determinação de massa de forragem em pastagens tropicais, pois seria necessário estudos que abrangessem diferentes estações do ano.

Bransby et al. (1977), estimando massa de forragem com o auxílio do disco medidor, constataram que uma mudança do estádio reprodutivo para o vegetativo em uma pastagem homogênea ou a mudança na composição botânica de um dossel misto podem alterar as curvas de calibração. Por isso, o disco medidor deve ser calibrado freqüentemente, assegurando estimativas confiáveis durante todas as estações do ano. Nesse mesmo trabalho, foram avaliados o efeito do tamanho e o peso do disco, utilizando quatro discos de tamanhos diferentes, mas com o mesmo peso e discos de tamanho idêntico, mas com pesos diferentes, e foram obtidos coeficientes de determinação de 0,79 a 0,94 entre as leituras do disco e a massa de forragem. Entretanto, não houve efeito significativo do peso nem do tamanho dos discos na precisão da calibração.

Oliveira et al. (2001), trabalhando com grama estrela (Cynodon nlemfuënsis var nlemfuënsis), sugeriram que a placa de alumínio do disco interferiu na baixa precisão do equipamento para a planta forrageira estudada, pois a pequena estrutura da haste dos perfilhos e das folhas curtas que a pastagem apresentava causou pequena resistência à compreensão da placa. 
Santillan et al. (1979), trabalhando com o disco medidor, verificaram que a idade das espécies tropicais estudadas (Paspalum notatum Flugge e Digitaria decumbens Stent) foi mais determinante da precisão do método que o estádio reprodutivo e a estação do ano, tendo sido observadas diferenças morfológicas menos acentuadas do que seria esperado considerando-se algumas gramíneas temperadas e as correspondentes mudanças de estação.

\subsubsection{Altura não comprimida}

A produção de forragem assim como as respostas de plantas forrageiras e animais sob pastejo possuem uma alta correlação com a quantidade e/ou altura do estrato de lâminas foliares no dossel forrageiro (Frame, 1981).

Assim, um outro método indireto para estimativa da massa de forragem em pastagens seria aquele baseado na altura do dossel, medida como sendo a distância entre a curvatura da folha mais alta no ponto de amostragem e o solo ou, também, na altura estendida de perfilhos individuais (Frame, 1981). Contudo, são as calibrações baseadas na altura da curvatura das folhas no topo do dossel as mais comumente utilizadas, especialmente para plantas temperadas (Hodgson, 1990).

A medição é baseada no uso de uma régua, geralmente graduada em centímetros, conhecida na literatura internacional como "sward stick". A medição de altura realizada dessa forma é proveniente de uma condição onde o dossel não é perturbado (comprimido), diferentemente daquela obtida através do prato ascendente e/ou disco medidor. Por se tratar de uma medida pontual, possui alta variabilidade, especialmente em pastos caracterizados por desuniformidade, típicos das situações de pastejo (Fagundes et al., 1999). Nessas condições, uma adaptação do método pode ser realizada através do uso de uma transparência, material muito leve e transparente, onde se toma a leitura do ponto mais alto e do ponto mais baixo do plano definido pela mesma quando colocada sobre o dossel. A altura do ponto de amostragem corresponde à média aritmética dessas duas leituras. Dessa maneira, a medida adaptada desse método é boa porque integra as variações pontuais de altura e fornece o valor "médio" de altura de um pequeno grupo de plantas ou perfilhos sem utilizar a densidade na determinação da 
massa de forragem. Isso ocorre pela leveza da transparência que acomoda-se no topo do dossel independentemente da densidade dele (Fagundes et al., 1999).

Assim, como os métodos do prato ascendente e do disco, este também precisa ser devidamente calibrado, uma vez que esta sujeito às mesmas restrições relativas a alterações morfológicas das plantas, estádios de desenvolvimento (vegetativo ou reprodutivo) e épocas do ano (item 2.4.3). 


\section{MATERIAL E MÉTODOS}

\subsection{Material}

\subsubsection{Espécie vegetal}

Segundo Mitidieri (1983), as espécies utilizadas no estudo classificam-se, de acordo com o "Sistema Engler", como: divisão Angiospermae; classe Monocotyledoneae; ordem Graminales; família Gramineae; subfamília Eragrostideae e tribo Chlorideae. São plantas pertencentes ao gênero Cynodon; espécie Cynodon dactylon cv 'Florakirk', Cynodon spp. cv 'Tifton 85 e Cynodon spp. cv. 'Coastcross'.

\subsubsection{Local do experimento}

O experimento foi conduzido na Unidade Experimental de Plantas Forrageiras (UEPF), em área do Departamento de Produção Animal da Escola Superior de Agricultura "Luiz de Queiroz", Universidade de São Paulo, no município de Piracicaba, Estado de São Paulo, localizado a $22^{\circ} 42^{\prime}$ latitude sul, $47^{\circ} 38^{\prime}$ longitude oeste e $546 \mathrm{~m}$ de altitude (Ometto, 1989). O período experimental foi de 08 de junho de 1998 a 25 de maio de 1999, sendo realizadas, durante esse período, amostragens mensais para fins de calibração dos métodos indiretos de avaliação de massa de forragem.

\subsubsection{Solo da área experimental}

O experimento foi instalado em solo classificado como Nitossolo Vermelho eutrófico, com horizonte $\mathrm{A}$ moderado de textura argilosa/muito argilosa. Devido à 
elevada fertilidade (Tabela 1) não foram realizadas calagem ou adubações potássicas ou fosfatadas no momento da implantação do experimento.

Tabela 1. Características químicas do solo da área experimental.

\begin{tabular}{cccccccccc}
\hline $\mathrm{pH}$ & $\mathrm{M} . \mathrm{O}$. & $\mathrm{P}$ & $\mathrm{K}$ & $\mathrm{Ca}$ & $\mathrm{Mg}$ & $\mathrm{H}+\mathrm{Al}$ & $\mathrm{SB}$ & $\mathrm{T}$ & $\mathrm{V}$ \\
$\mathrm{CaCl}_{2}$ & $\mathrm{~g} \cdot \mathrm{dm}^{-3}$ & $\mathrm{mg} \cdot \mathrm{dm}^{-3}$ & - & & & & \\
\hline 5,4 & 37,0 & 99 & 4,6 & 75 & 26 & 30 & 106 & 136 & 78,0 \\
\hline
\end{tabular}

\subsubsection{Clima}

Conforme o sistema Köppen, o clima da região de Piracicaba pode ser classificado como Cwa, isto é, mesotérmico úmido, subtropical de inverno seco, onde a temperatura do mês mais frio é inferior a $18{ }^{\circ} \mathrm{C}$ e a do mês mais quente ultrapassa os 22 ${ }^{\circ} \mathrm{C}$ (Brasil, 1960). Os dados climáticos referentes ao período experimental encontram-se na Tabela 2 e nas Figuras 2, 3 e 4. Os dados foram obtidos no posto meteorólogico do Departamento de Ciências Exatas da ESALQ-USP, distante cerca de $500 \mathrm{~m}$ da área experimental. 
Tabela 2. Temperaturas médias mensais do ar (máxima média, mínima média e média), precipitação pluvial e insolação diária média durante o período experimental (de junho/98 à maio/99) e comparação com os dados dos últimos 80 anos.

\begin{tabular}{|c|c|c|c|c|c|}
\hline \multirow[b]{2}{*}{ Mês/ano } & \multicolumn{3}{|c|}{ Temperatura $\left({ }^{\circ} \mathrm{C}\right)$} & \multirow[b]{2}{*}{$\begin{array}{l}\text { Precipitação } \\
\text { média } \\
\text { (mm chuva) }\end{array}$} & \multirow[b]{2}{*}{$\begin{array}{l}\text { Insolação } \\
\text { média* } \\
\text { (h/dia) }\end{array}$} \\
\hline & $\begin{array}{l}\text { Máxima } \\
\text { média }\end{array}$ & $\begin{array}{l}\text { Mínima } \\
\text { média }\end{array}$ & Média & & \\
\hline Junho/98 & 24,1 & 9,9 & 17,0 & 26,6 & 6,7 \\
\hline Média (80 anos - junho) & 24,9 & 10,3 & 17,6 & 43,7 & 7,1 \\
\hline Julho/98 & 25,9 & 10,8 & 18,4 & 13,9 & 7,2 \\
\hline Média (80 anos - julho) & 25,3 & 9,5 & 17,4 & 27,2 & 7,8 \\
\hline Agosto/98 & 27,4 & 14,4 & 20,9 & 21,8 & 6,2 \\
\hline Média (80 anos - agosto) & 27,3 & 11,0 & 19,2 & 29,9 & 8,1 \\
\hline Setembro/98 & 27,7 & 15,3 & 21,5 & 89,3 & 5,7 \\
\hline Média (80 anos - setembro) & 28,1 & 13,4 & 20,7 & 63,7 & 6,8 \\
\hline Outubro/98 & 27,06 & 16,33 & 21,70 & 183,10 & 5,43 \\
\hline Média (80 anos - outubro) & 28,90 & 15,57 & 22,23 & 111,28 & 6,87 \\
\hline Novembro/98 & 30,04 & 16,45 & 23,24 & 26,60 & 7,79 \\
\hline Média (80 anos- novembro) & 29,57 & 16,68 & 23,09 & 130,01 & 7,42 \\
\hline Dezembro-98 & 30,01 & 19,21 & 24,61 & 292,60 & 6,06 \\
\hline Média (80 anos - dezembro) & 29,61 & 18,15 & 23,87 & 200,16 & 6,58 \\
\hline Janeiro/99 & 31,42 & 18,98 & 25,20 & 210,80 & 7,70 \\
\hline Média (80 anos - janeiro) & 29,92 & 18,19 & 24,05 & 142,45 & 6,84 \\
\hline Fevereiro/99 & 30,73 & 20,05 & 25,41 & 198,30 & 5,37 \\
\hline Média (80 anos - fevereiro) & 30,23 & 19,02 & 24,61 & 185,89 & 6,54 \\
\hline Março/99 & 31,42 & 18,98 & 25,20 & 210,80 & 7,70 \\
\hline Média (80 anos - março) & 29,96 & 18,19 & 24,05 & 142,45 & 6,84 \\
\hline Abril/99 & 28,52 & 15,20 & 21,86 & 89,0 & 8,09 \\
\hline Média (80 anos - abril) & 28,32 & 15,36 & 21,81 & 64,79 & 7,50 \\
\hline Maio/99 & 25,42 & 11,18 & 18,30 & 51,30 & 7,45 \\
\hline Média ( 80 anos - maio) & 26,09 & 12,08 & 19,06 & 52,66 & 7,25 \\
\hline
\end{tabular}

Fonte: Arquivos do Departamento de Ciências Exatas - ESALQ/USP (2001)

* Dados históricos de 77 anos 


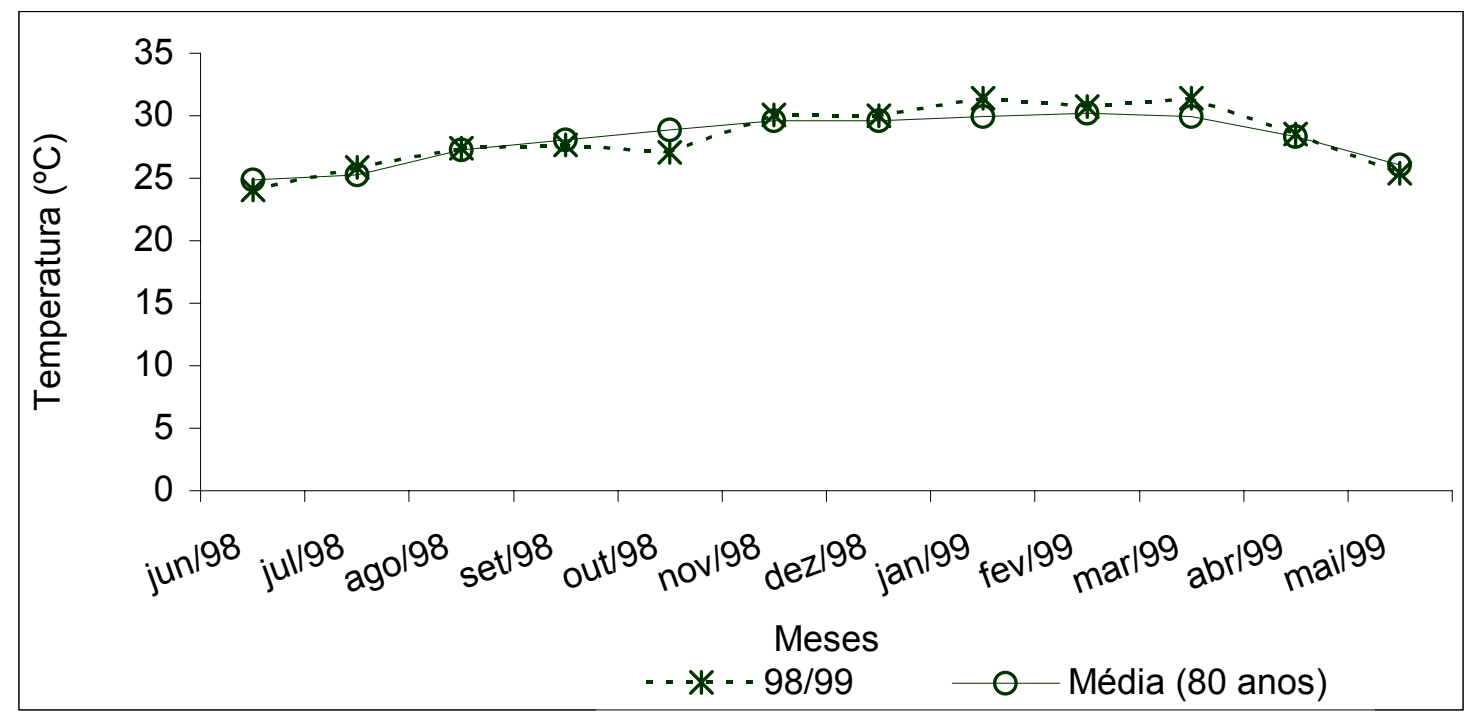

Figura 2 - Distribuição das temperaturas médias durante o período experimental (Junho/98 a Maio/99) comparadas com aquelas dos últimos 80 anos.

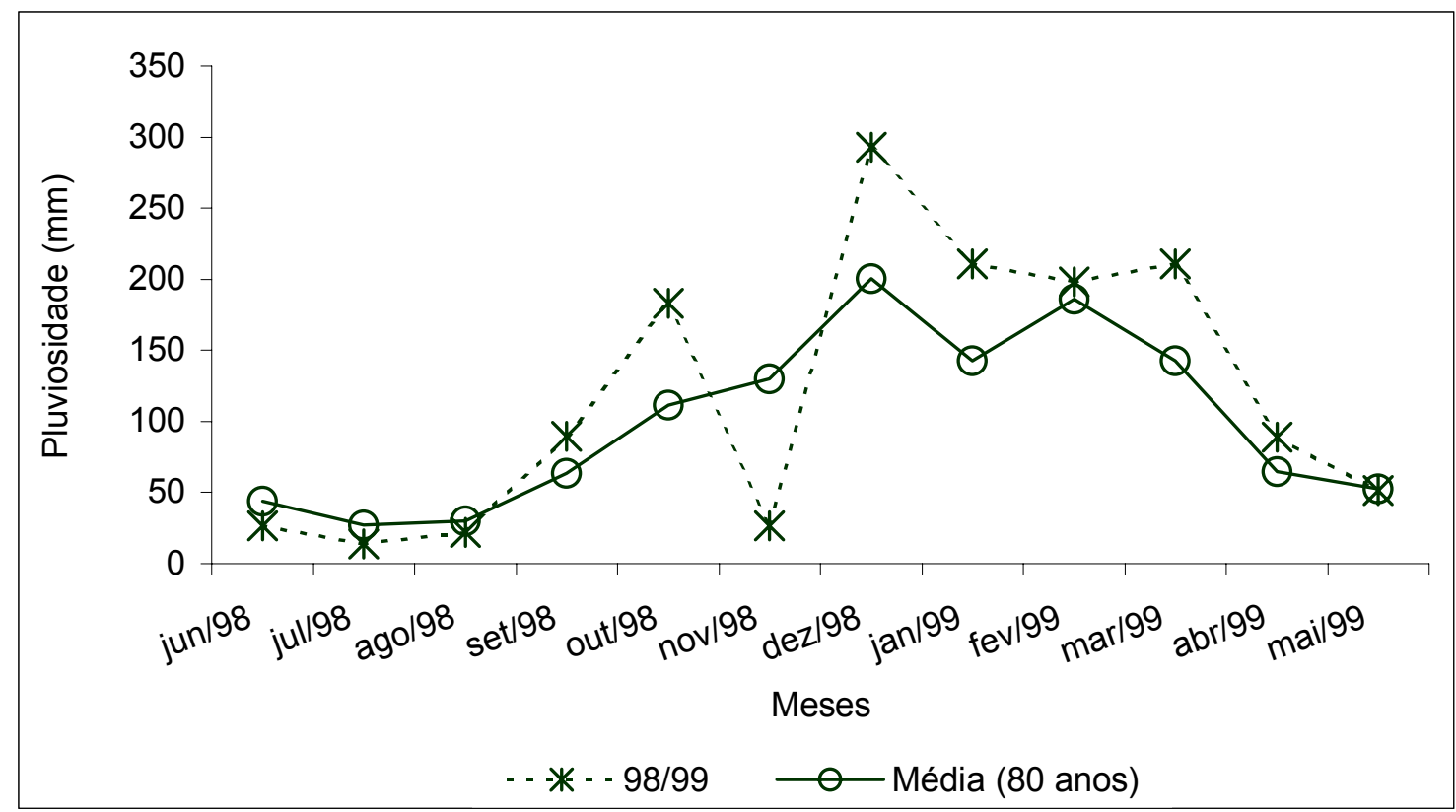

Figura 3 - Distribuição da precipitação durante o período experimental (Junho/98 à Maio/99) comparada com aquela dos últimos 80 anos. 


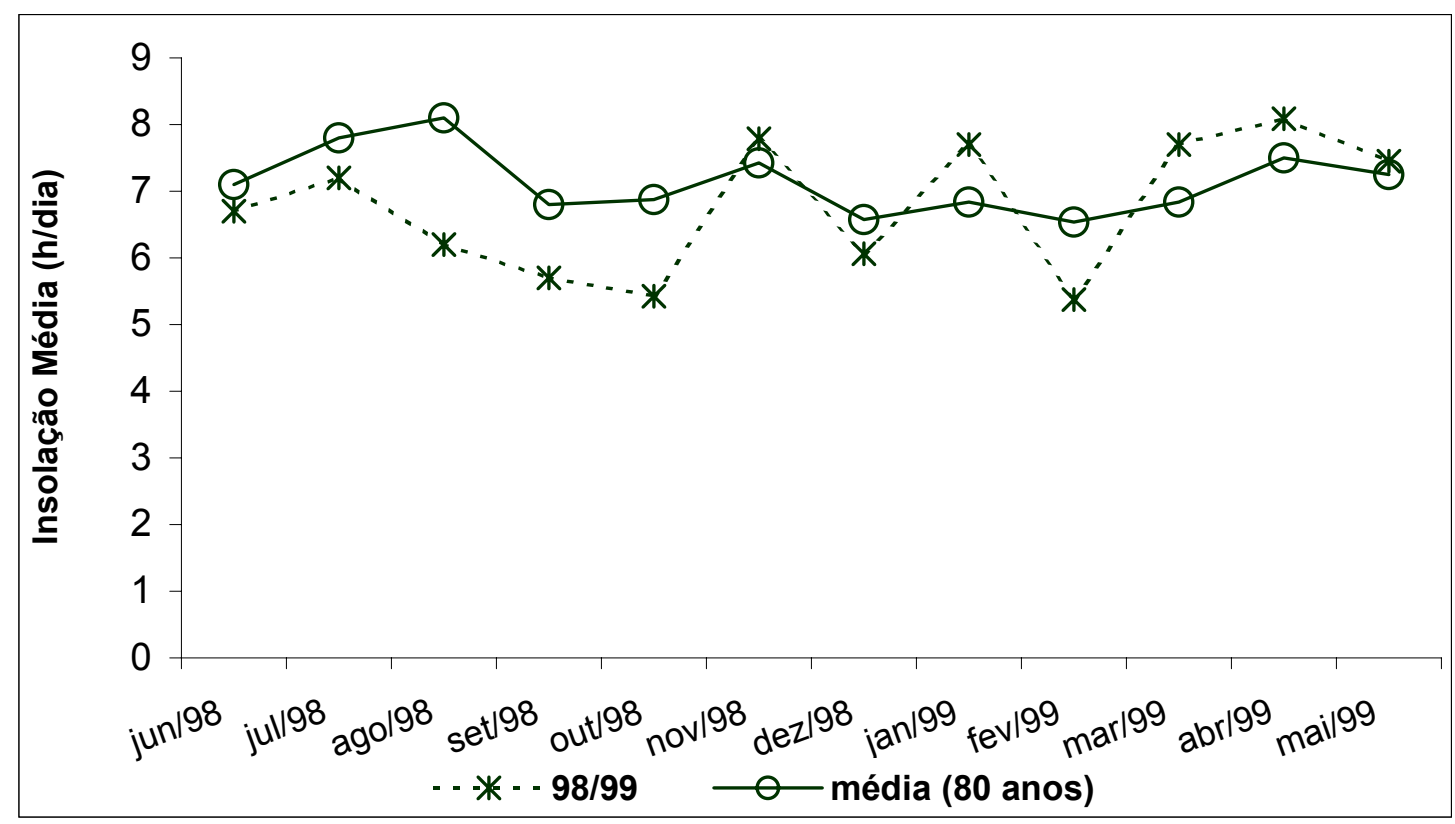

Figura 4 - Distribuição das insolações médias durante o período experimental (Junho/98 a Maio/99) comparadas com aquelas dos últimos 77 anos.

\subsubsection{Pastagens}

Os pastos foram implantados em março de 1996 através de mudas, sendo que, devido às adversidades climáticas e ao baixo percentual de pegamento, fez-se o replantio de algumas parcelas durante os meses de fevereiro e março de 1997. Em várias ocasiões durante o estabelecimento fez-se necessário a limpeza da área em virtude da infestação com plantas invasoras, especialmente Brachiaria decumbens Stapf, Cyperus spp., Panicum maximum Jacq. e Cynodon dactylon (L) Pers. (grama estrela). Adubações nitrogenadas foram realizadas durante o decorrer do ano de 1997, as quais totalizaram $150 \mathrm{~kg} \mathrm{~N} \mathrm{ha}^{-1}$ na forma de sulfato de amônio.

Em janeiro de 1998 realizou-se um corte de uniformização, seguido de uma adubação com $40 \mathrm{~kg} \mathrm{~N} \mathrm{ha}^{-1}$ na forma de sulfato de amônio, além do controle de invasoras. Em fevereiro de 1998 a área experimental sofreu uma infestação de lagarta do cartucho (Spodoptera frugiperda Smith) e cigarrinha das pastagens (Deois spp. e Zulia entreriana Berg.), a qual foi controlada com o inseticida Deltamethrin, na dosagem de $7,5 \mathrm{~g}$ i. a. ha ${ }^{-1}$, juntamente com Metarhizium, na dosagem de 800 gramas/hectare, em 19 
de fevereiro de 1998. Um novo corte de uniformização foi então realizado em março de 1998. No entanto, ocorreu um novo ataque da lagarta juntamente com a cigarrinha das pastagens (Deois spp. e Zulia entreriana), e nova aplicação de inseticida foi feita, em 2 de abril de 1998, utilizando-se, desta vez, Chlorpyrifos, na dosagem de 1L/hectare. Após o controle da infestação de pragas as pastagens foram deixadas rebrotar até que as alturas especificadas para cada tratamento fossem atingidas, oportunidade na qual foi iniciado o pastejo. Foram decorridos cerca de seis meses (junho a setembro/1998) com os pastos sendo mantidos sob os regimes de desfolha planejados antes que a primeira avaliação fosse realizada.

\subsection{Métodos}

\subsubsection{Delineamento experimental e tratamentos}

$\mathrm{O}$ experimento foi realizado seguindo um delineamento em blocos completos casualizados, com parcelas subdivididas (split-plot). Os tratamentos corresponderam a combinações entre três cultivares de Cynodon spp. ('Tifton-85', 'Florakirk' e 'Coastcross'), os quais foram alocados às parcelas, e quatro condições de pasto geradas por ovinos sob regime de lotação contínua e taxa de lotação variável, alocadas nas subparcelas. Cada condição de pasto correspondeu a uma altura média do relvado de 5, 10, 15 e $20 \mathrm{~cm}$ mantida "constante" através da adição ou retirada de animais das unidades experimentais durante o transcorrer do experimento. Nesse arranjo foram utilizadas quatro repetições. Assim, o ensaio apresentou um total de 48 unidades experimentais (4 blocos x 12 unidades/bloco) com uma área de, aproximadamente, $400 \mathrm{~m}^{2}$ cada, separadas por telas de $1,20 \mathrm{~m}$ de altura para delimitação dos piquetes (unidades experimentais) e contenção dos animais. A área experimental total compreendeu 2,0 ha (Figura 5, Foto 1). 


BLOCO I
\begin{tabular}{|c|c|c|}
\hline T 10 & F 15 & C 10 \\
\hline T 15 & F 10 & C 05 \\
\hline T 20 & F 05 & C 15 \\
\hline T 05 & F 20 & C 20 \\
\hline
\end{tabular}

BLOCO II

\begin{tabular}{|c|c|c|}
\hline F 05 & T 10 & C 10 \\
\hline F 10 & T 15 & C 20 \\
\hline F 15 & T 20 & C 15 \\
\hline F 20 & T 05 & C 05 \\
\hline
\end{tabular}

BLOCO III

\begin{tabular}{|l|l|l|}
\hline F 20 & T 15 & C 10 \\
\hline F 05 & T 20 & C 15 \\
\hline F 15 & T 10 & C 20 \\
\hline F 10 & T 05 & C 05 \\
\hline
\end{tabular}

BLOCO IV

\begin{tabular}{|l|l|l|}
\hline T 20 & F 05 & C 05 \\
\hline T 15 & F 10 & C 20 \\
\hline T 10 & F 20 & C 10 \\
\hline T 05 & F 15 & C 15 \\
\hline
\end{tabular}

Figura 5 - Representação esquemática da distribuição dos tratamentos na área experimental. T: Tifton 85; F: Florakirk; C: Coastcross. Alturas (cm): 5, 10,15 e 20.

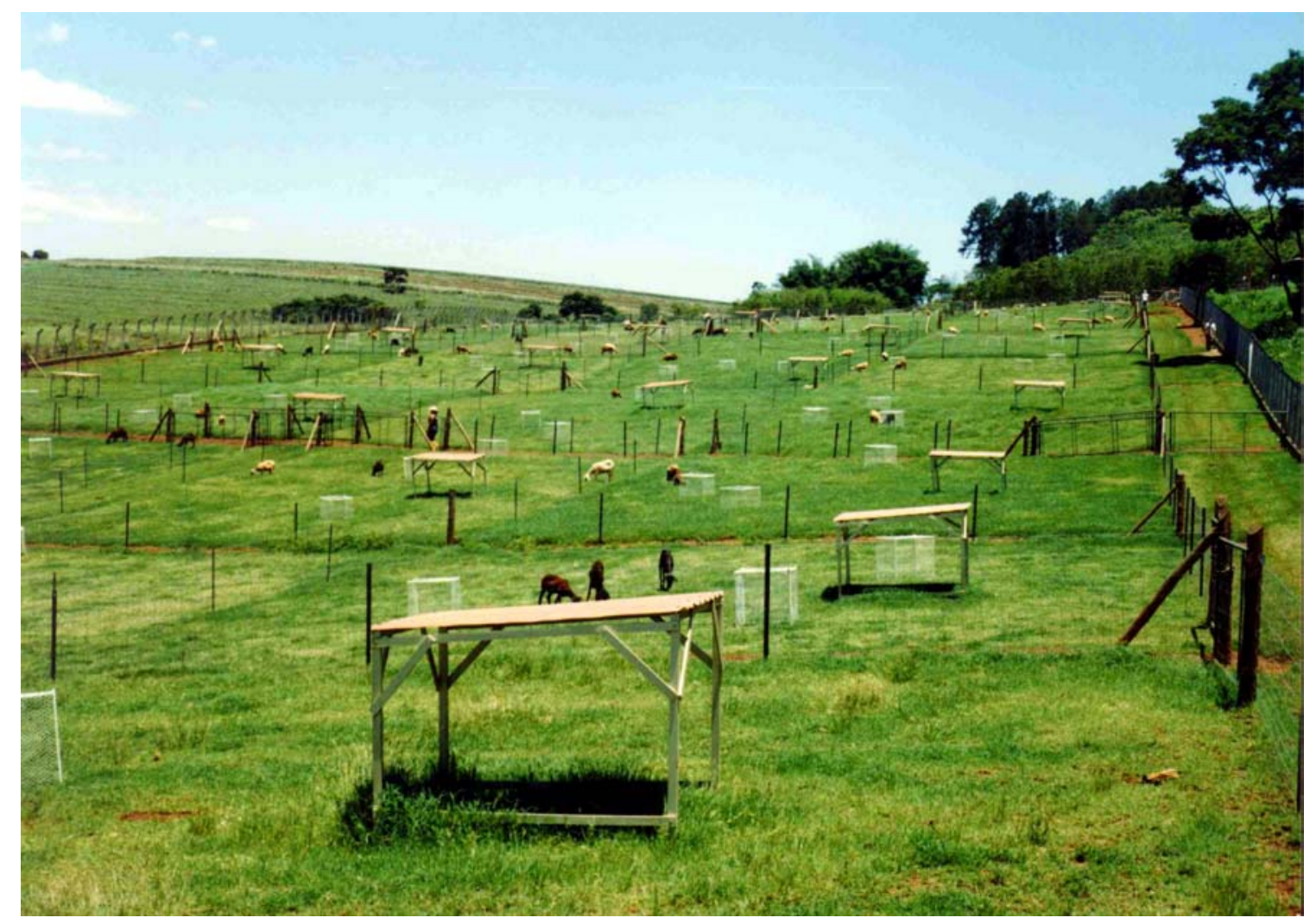

Foto 1 - Vista geral da área experimental após a implantação e início do experimento

\subsubsection{Instalação e monitoramento das condições experimentais}

Em 3 de junho de 1998 os animais foram alocados às unidades experimentais que haviam atingido a altura pré-determinada para cada tratamento. À medida que as demais unidades experimentais atingiam a altura desejada, animais eram colocados, 
dando início ao pastejo. No ano de 1998 foram realizadas 4 adubações nitrogenadas com sulfato de amônio. A primeira adubação foi feita em 8 de julho (40 $\left.\mathrm{kg} \mathrm{N} \mathrm{ha}^{-1}\right)$, a segunda

em 19 de setembro (40 $\left.\mathrm{kg} \mathrm{N} \mathrm{ha}^{-1}\right)$, a terceira em 21 de outubro $\left(50 \mathrm{~kg} \mathrm{~N}^{-1}\right)$ e a quarta em 7 de dezembro (25 $\mathrm{kg} \mathrm{N} \mathrm{ha}^{-1}$ ). Em 1999, até a última coleta de dados em julho, foram realizadas duas adubações nitrogenadas. A primeira em 23 de fevereiro $\left(50 \mathrm{~kg} \mathrm{~N} \mathrm{ha}^{-1}\right)$ e a segunda em 5 de março $\left(75 \mathrm{~kg} \mathrm{~N} \mathrm{ha}^{-1}\right)$.

A condição dos pastos (altura média do relvado) foi monitorada semanalmente através da tomada de 20 leituras em cada unidade experimental com o "rising plate meter", ou prato ascendente, duas vezes por semana, obtendo-se a altura comprimida média. Uma vez por mês era feita a calibração da altura comprimida com a altura não comprimida (régua), gerando o valor de altura usado como referência para o monitoramento dos tratamentos (Foto 2). Animais foram adicionados ou removidos das unidades experimentais no caso da altura estar acima ou abaixo da desejada, respectivamente.

\subsubsection{Calibração entre a altura comprimida e altura não comprimida}

Uma vez por mês era realizada a calibração entre a altura comprimida e a altura não comprimida do pasto. Durante a calibração eram realizadas 20 medições com o "rising plate meter" e 12 leituras de altura não comprimida por unidade experimental. Esta última altura era medida utilizando-se uma transparência que, quando colocada sobre a pastagem, tinha sua altura mais baixa e a mais alta em relação ao solo medidas com uma régua. Assim, cada leitura não comprimida correspondia à média entre os valores mais alto e mais baixo. Com os valores das alturas eram gerados fatores mensais de conversão que, multiplicados pelas alturas comprimidas, forneciam a altura da pastagem utilizada como referência para o monitoramento da condição do pasto e ajustes nas taxas de lotação (Foto 2). 


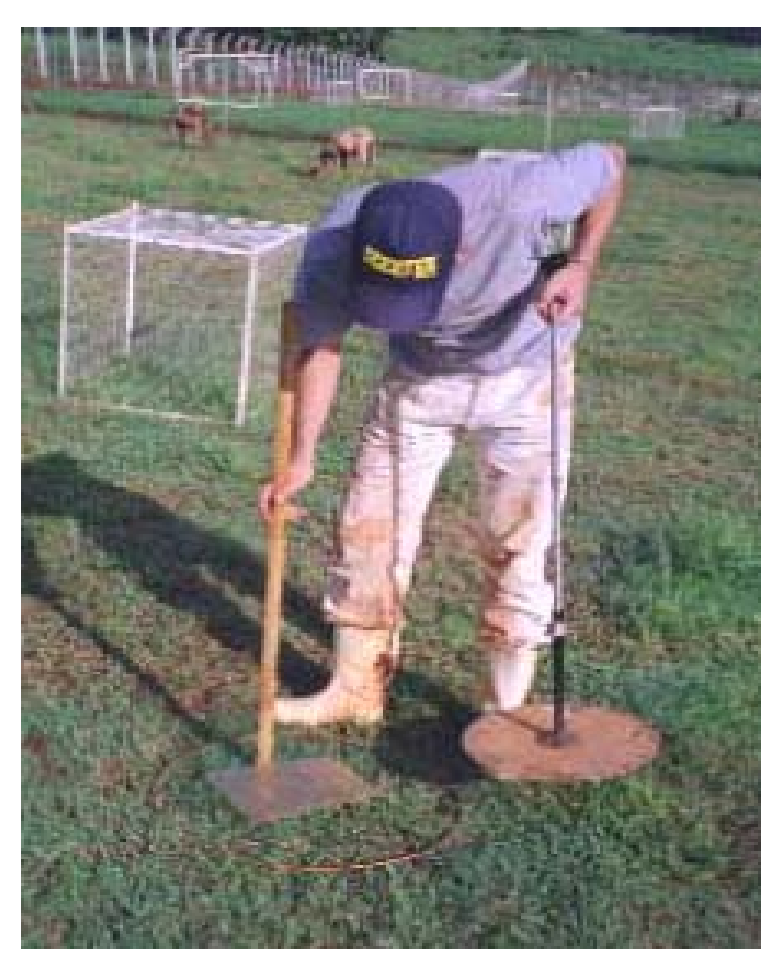

Foto 2 - Medição da altura do pasto com transparência e régua (altura não comprimida) e com o "rising plate meter" (altura comprimida).

\subsection{Métodos utilizados para estimativa de massa de forragem}

Para avaliação da massa de forragem por unidade de área $\left(\mathrm{kg}\right.$ de $\left.\mathrm{MS} / \mathrm{m}^{2}\right)$ foram utilizados 3 círculos de $0,25 \mathrm{~m}^{2}$ cada. Os círculos foram colocados em locais da unidade experimental que correspondiam aos pontos mais alto, mais baixo e na altura média da unidade experimental no dia da avaliação. Antes do corte da forragem contida dentro de cada círculo (método direto), tomou-se uma leitura com a transparência (item 3.2.3 altura não comprimida) e uma leitura com o prato ascendente (altura comprimida), os dois métodos indiretos utilizados (Foto 2). Em seguida a massa de forragem foi cortada no nível do solo. As amostras foram acondicionadas em sacos plásticos e levadas para câmara fria. Cada amostra foi lavada, colocada em bandejas de metal e levada à estufa para secagem a $65{ }^{\circ} \mathrm{C}$ por dois dias e, posteriormente, pesada. Este procedimento permitiu que para as alturas de pasto estudadas $(5,10,15$ e $20 \mathrm{~cm})$ fosse gerada uma amplitude de valores de massa de forragem e leituras correspondentes de altura 
comprimida e não comprimida bastante compreensiva para cada cultivar contido dentro de cada bloco. O prato ascendente utilizado era de alumínio e de fabricação neozelandesa, marca Ashgrove, com diâmetro médio do disco de 35,5 centímetros e massa 480,2 gramas.

\subsection{Tratamento matemático dos dados e análise estatística}

A proposta da análise realizada sobre os dados referentes aos métodos indiretos testados foi avaliar se (i) uma equação única poderia ser utilizada para os três cultivares estudados, dadas as similaridades morfológicas e estruturais dos mesmos, e (ii) se uma equação única poderia ser utilizada para o ano todo, ou haveria a necessidade de equações específicas para períodos definidos do ano. Se este fosse o caso, quais seriam

as épocas do ano que poderiam utilizar as mesmas equações e, portanto, orientar o agrupamento dos dados coletados de forma mensal para gerar as equações de calibração desejadas.

Para tanto, os pares de dados "massa de forragem x altura não comprimida" e "massa de forragem x altura comprimida" foram tabulados separadamente e uma análise de regressão simples entre eles foi realizada através do PROC REG do pacote estatístico SAS (Statistical Analysis System) versão 6.12 para Windows (SAS Institute, 1988). Dessa forma foram geradas equações de calibração entre massa e altura do pasto (diferentes métodos) do tipo $\mathrm{M}=\mathrm{a}+\mathrm{b} . \mathrm{H}$, onde $\mathrm{H}$ é a altura medida e $\mathrm{M}$ é a massa de forragem ( $\mathrm{kg} \mathrm{MS} / \mathrm{ha}$ ) calculada a partir da altura $\mathrm{H}$. As equações resultantes eram específicas para cada bloco e para cada cultivar.

Os valores de intercepto (valor "a") e de coeficiente angular (valor "b") gerados foram submetidos a análise estatística de variância através do PROC MIXED do SAS. Esta análise foi realizada utilizando-se um modelo onde as causas de variação foram cultivar, bloco e mês do ano, respeitando um delineamento de blocos completos casualizados com quatro repetições, com medidas repetidas no tempo. As médias finais por cultivar e por mês do ano foram geradas e comparadas através do LSMEANS, com um nível de significância de 5\%. Com base nesta comparação das médias de intercepto e de coeficiente angular para cada cultivar em cada mês do ano determinou-se a 
necessidade e a natureza do agrupamento dos dados originais para a análise final de regressão, que gerou as curvas de calibração de cada método para o período experimental considerado.

Todas as equações geradas foram regressões lineares, uma vez que esse é o padrão de resposta descrito na literatura para ambos os métodos estudados. Vale ressaltar que um modelo quadrático foi testado, não resultando em melhoria alguma na significância e precisão das equações de calibração geradas. 


\section{RESULTADOS E DISCUSSÃO}

\subsection{Análise dos dados para reconhecimento de possíveis padrões de agrupamento}

Inicialmente todos os dados foram submetidos a uma análise de regressão simples que gerou equações do tipo $\mathrm{y}=\mathrm{a}+\mathrm{bx}$, onde $\mathrm{y}=$ massa de forragem em $\mathrm{Kg}$ $\mathrm{MS} / \mathrm{ha}$ e $\mathrm{x}=$ altura média do pasto medida pelos dois métodos estudados. Essas equações foram geradas para cada um dos dois métodos indiretos de estimativa de massa de forragem (prato ascendente e régua) e, dentro de método, para cada um dos cultivares e meses do ano. Foram gerados os valores de intercepto (a) e coeficiente angular (b), os quais foram submetidos a análise de variância segundo um delineamento experimental de blocos completos ao acaso com quatro repetições. O objetivo dessa análise inicial foi avaliar possíveis diferenças entre cultivares e meses do ano para os valores de intercepto e coeficiente angular das curvas de calibração como forma de orientação sobre possíveis padrões de agrupamento de dados (cultivares e/ou épocas do ano) para geração de equações de calibração mais abrangentes e robustas.

\subsubsection{Método do prato ascendente}

Houve diferença entre cultivares $(\mathrm{P}<0,05)$ para valores médios de intercepto e de coeficiente angular das equações de calibração geradas inicialmente para os doze meses do período experimental (Tabela 3). 
Tabela 3. Valores médios do intercepto ( $\mathrm{kg} \mathrm{MS} / \mathrm{ha}$ ) e do coeficiente angular $(\mathrm{kg} \mathrm{MS} / \mathrm{cm})$ das equações de calibração do método do prato ascendente para os cultivares de Cynodon spp. durante o período experimental.

\begin{tabular}{ccc}
\hline Cultivar & Intercepto & Coeficiente Angular \\
\hline Florakirk & $2715^{\mathrm{a}}$ & $133,4^{\mathrm{b}}$ \\
Tifton 85 & $2380^{\mathrm{a}}$ & $162,7^{\mathrm{a}}$ \\
Coastcross & $1802^{\mathrm{b}}$ & $146,8^{\mathrm{ab}}$ \\
EPM $^{*}$ & 155,0 & 5,79 \\
\hline
\end{tabular}

${ }^{*} \mathrm{EPM}=$ erro padrão da média

Médias na mesma coluna seguidas da mesma letra não diferem entre si $(\mathrm{P}>0,05)$

Florakirk e Tifton 85 apresentaram valores de intercepto semelhantes e superiores a Coastcross. Contudo, um padrão diferente foi observado com relação aos valores de coeficiente angular, com Tifton 85 e Coastcross apresentando valores semelhantes e diferindo de Florakirk (Tabela 3). Este fato indica que a geração de uma curva de calibração comum para os três cultivares não seria recomendável nem, tampouco, para qualquer agrupamento possível entre eles, razão pela qual análises específicas para cada cultivar foram realizadas durante o restante da avaliação deste método indireto de estimativa de massa de forragem. Esses resultados são condizentes com aqueles de Aiken \& Bransby (1992); Santillan at al. (1979) e Bransby et al. (1997). Normalmente, em função da semelhança entre os cultivares, esses têm seu manejo de corte e/ou pastejo realizado de forma idêntica ao longo do ano em condições de campo ou fazenda. A simples avaliação dos valores de intercepto e de coeficiente angular revela que essa generalização é equivocada e que pode vir a comprometer a eficiência de utilização, produtividade e longevidade dos pastos formados por esses cultivares.

Diferenças em intercepto e coeficiente angular podem ser explicadas pela variação em estrutura dos pastos (Hodgson, 1990). Avaliação e descrição das características estruturais dos pastos formados pelos cultivares estudados foram realizadas por Fagundes (1999), Carnevalli (1999), Carvalho (2000), Sbrissia (2000) e Pinto (2000) em experimentos realizados de forma concomitante na mesma área experimental. Carnevalli (1999) relatou valores de densidade "bulk" do pasto ( $\mathrm{Kg}$ 
MS/cm.ha) diferentes para os cultivares avaliados quando submetidos a condições semelhantes de manejo do pastejo, sendo que Tifton 85 e Florakirk apresentaram valores mais elevados que Coastcross. A variação nessa única característica estrutural do pasto poderia explicar a maior parte das diferenças observadas entre cultivares para os valores de intercepto e coeficiente angular constantes na Tabela 3, uma vez que relaciona, em um mesmo parâmetro, duas características estruturais muito importantes, massa de forragem e altura do pasto. Segundo a autora, o principal determinante da variação da densidade "bulk" foi a proporção de material morto e hastes existentes no perfil do dossel de cada pasto, fatores esses que também variaram entre meses dos ano. Fagundes et al. (2001) observaram o mesmo padrão de comportamento para valores de índice de área foliar (IAF) dos pastos, ou seja, valores superiores de IAF para Tifton 85 e Florakirk relativamente a Coastcross. Observaram também variações compensatórias àquelas em IAF em termos de coeficiente de extinção luminosa $(\mathrm{k})$, de forma que Coastcross e Florakirk apresentaram valores de k superiores a Tifton 85, refletindo um maior ângulo foliar como forma de compensação pelo menor valor de IAF dos pastos, compensação essa que minimizou as diferenças observadas em interceptação luminosa entre os cultivares. A análise conjunta dos dados de Fagundes (1999) e Carnevalli (1999) revela uma variação da densidade de área foliar ao longo do perfil do dossel dos cultivares estudados, variação essa que pode influir diretamente nas taxas de acúmulo e consumo de matéria seca, eficiência de utilização, proporção de haste e folha e de material vivo e morto na base do pasto. Adicionalmente, Carvalho (2000) relatou diferenças em densidade populacional de perfilhos e padrão de comportamento fisiológico relacionadas a eventos de florescimento ao longo do ano que corroboraram as variações em densidade "bulk" dos pastos observadas por Carnevalli (1999). Pastos mantidos em condições idênticas de manejo (situações de steady state caracterizadas por alturas de pasto de 5, 10, 15 e $20 \mathrm{~cm}$ ) apresentaram densidades populacionais de perfilhos diferentes, que tenderam a ser compensadas por ajustes no tamanho e peso dos perfilhos existentes (Sbrissia, 2000). As variações estruturais nas pastagens corroboram os resultados encontrados por Gonzáles et al. (1990) e Carnevalli \& Da Silva (1999).

Quanto a variação dos valores médios de intercepto (Tabela 4) e coeficiente angular (Tabela 5) ao longo do período experimental, foram observadas diferenças entre 
os meses do ano $(\mathrm{P}<0,05)$, exceção feita aos valores de coeficiente angular para Tifton 85.

Tabela 4. Valores médios de intercepto (kg MS/ha) das curvas de calibração do prato ascendente para os cultivares Florakirk, Tifton 85 e Coastcross durante o período experimental.

\begin{tabular}{cccc}
\hline Meses & Florakirk & Tifton 85 & Coastcross \\
\hline Junho/98 & $4063^{\mathrm{a}}$ & $3090^{\mathrm{ab}}$ & $2146^{\mathrm{bc}}$ \\
Julho/98 & $2776^{\mathrm{bcd}}$ & $3016^{\mathrm{ab}}$ & $2115^{\mathrm{bc}}$ \\
Agosto/98 & $2628^{\mathrm{bcd}}$ & $2452^{\mathrm{bc}}$ & $1809^{\mathrm{bcd}}$ \\
Setembro/98 & $2749^{\mathrm{bcd}}$ & $2815^{\mathrm{b}}$ & $1874^{\mathrm{bcd}}$ \\
Outubro/98 & $3528^{\mathrm{ab}}$ & $2475^{\mathrm{bc}}$ & $2325^{\mathrm{b}}$ \\
Novembro/98 & $4049^{\mathrm{a}}$ & $3949^{\mathrm{a}}$ & $3251^{\mathrm{a}}$ \\
Dezembro/98 & $3265^{\mathrm{abc}}$ & $2665^{\mathrm{bc}}$ & $1947^{\mathrm{bcd}}$ \\
Janeiro/99 & $1642^{\mathrm{ef}}$ & $1801^{\mathrm{bcde}}$ & $764^{\mathrm{e}}$ \\
Fevereiro/99 & $1519^{\mathrm{f}}$ & $1142^{\mathrm{e}}$ & $816^{\mathrm{e}}$ \\
Março/99 & $1854^{\mathrm{def}}$ & $1435^{\mathrm{de}}$ & $1349^{\mathrm{cd}}$ \\
Abril/99 & $2019^{\mathrm{def}}$ & $1364^{\mathrm{de}}$ & $1139^{\mathrm{de}}$ \\
Maio/99 & $2484^{\mathrm{cde}}$ & $2360^{\mathrm{bcd}}$ & $2088^{\mathrm{bcd}}$ \\
EPM $^{*}$ & 359,5 & 359,5 & 359,5 \\
\hline
\end{tabular}

$\mathrm{EPM}=$ erro padrão da média

Médias na mesma coluna seguidas da mesma letra não diferem entre si $(\mathrm{P}>0,05)$ 
Tabela 5. Valores médios de coeficiente angular $(\mathrm{kg} \mathrm{MS} / \mathrm{cm})$ das curvas de calibração do prato ascendente para os cultivares Florakirk, Tifton 85 e Coastcross durante o período experimental.

\begin{tabular}{cccc}
\hline Meses & Florakirk & Tifton 85 & Coastcross \\
\hline Junho/98 & $164,7^{\mathrm{a}}$ & $187,5^{\mathrm{a}}$ & $219,1^{\mathrm{a}}$ \\
Julho/98 & $108,0^{\mathrm{ab}}$ & $135,0^{\mathrm{a}}$ & $114,8^{\mathrm{b}}$ \\
Agosto/98 & $136,0^{\mathrm{ab}}$ & $157,2^{\mathrm{a}}$ & $152,3^{\mathrm{b}}$ \\
Setembro/98 & $119,4^{\mathrm{ab}}$ & $152,3^{\mathrm{a}}$ & $137,1^{\mathrm{b}}$ \\
Outubro/98 & $90,1^{\mathrm{b}}$ & $179,3^{\mathrm{a}}$ & $111,5^{\mathrm{b}}$ \\
Novembro/98 & $142,5^{\mathrm{ab}}$ & $137,8^{\mathrm{a}}$ & $130,3^{\mathrm{b}}$ \\
Dezembro/98 & $127,5^{\mathrm{ab}}$ & $177,4^{\mathrm{a}}$ & $139,8^{\mathrm{b}}$ \\
Janeiro/99 & $142,0^{\mathrm{ab}}$ & $137,7^{\mathrm{a}}$ & $158,1^{\mathrm{ab}}$ \\
Fevereiro/99 & $146,1^{\mathrm{ab}}$ & $163,8^{\mathrm{a}}$ & $164,3^{\mathrm{ab}}$ \\
Março/99 & $146,3^{\mathrm{ab}}$ & $183,3^{\mathrm{a}}$ & $142,3^{\mathrm{b}}$ \\
Abril/99 & $127,6^{\mathrm{ab}}$ & $169,0^{\mathrm{a}}$ & $144,3^{\mathrm{b}}$ \\
Maio/99 & $150,4^{\mathrm{ab}}$ & $172,6^{\mathrm{a}}$ & $148,0^{\mathrm{b}}$ \\
EPM $^{*}$ & 21,96 & 21,96 & 21,96 \\
\hline
\end{tabular}

$\mathrm{EPM}=$ erro padrão da média

Médias na mesma coluna seguidas da mesma letra não diferem entre si $(\mathrm{P}>0,05)$

As variações observadas nos valores de intercepto e coeficiente angular ao longo do período experimental foram consequência da variação em estrutura dos pastos ao longo do ano (Frame, 1981; Aiken \& Bransby, 1992; Santillan at al. 1979 e Bransby, et al. 1997). Fagundes (1999) e Carnevalli (1999) descreveram as alterações em estrutura dos pastos de Florakirk, Tifton 85 e Coastcross e Carnevalli (1999) relacionou-as às variações em densidade "bulk" observadas. O principal componente morfológico do perfil dos pastos relacionado com as variações em estrutura ao longo do ano foi a proporção de material morto no perfil do dossel, particularmente concentrado na base dos pastos, próximo ao solo, razão pela qual os valores de intercepto tenderam a seguir o mesmo padrão de comportamento, independente de cultivar, ou seja, valores 
aumentando de julho a novembro, diminuindo de dezembro a fevereiro e aumentando novamente de março a junho. Segundo Carnevalli (1999), esse padrão de variação foi consequência da variação na disponibilidade de temperatura e precipitação, ou seja, aumento das chuvas e da temperatura média ambiente durante a primavera, culminando com os valores mais elevados durante o verão e, então, valores decrescentes durante o outono e inverno. Maiores temperaturas médias e maior disponibilidade de água e umidade relativa são fatores propícios ao desenvolvimento de microrganismos, responsáveis pela decomposição da matéria orgânica sobre a superfície do solo.

Com relação aos coeficientes angulares, houve uma variação muito discreta ao longo do ano para Florakirk e Coastcross, com Tifton 85 comportando-se de maneira bastante uniforme. Excetuando-se os valores de coeficiente angular no mês de junho para os cultivares Florakirk e Coastcross, mês de intenso florescimento (Carvalho, 2000) e alteração em estrutura do pasto por alteração do estádio fisiológico das plantas (Carnevalli, 1999; Sbrissia, 2000), os valores de coeficiente angular nos demais meses do ano também mostraram-se bastante semelhantes, como para Tifton 85, cultivar que apresentou processo de florescimento bastante modesto e inferior aos outros dois cultivares. Assim, nota-se que o efeito de época do ano foi maior sobre o intercepto das curvas de calibração do método do prato ascendente, com pequena influência sobre os valores de coeficiente angular nos pastos mantidos predominantemente no estádio vegetativo de desenvolvimento. Os resultados encontrados estão de acordo com aqueles de Gomes et al. (2000), Santillan at al. (1979) e Bransby at al. (1977). Esse fato revela uma forte influência potencial de práticas de manejo e localidade sobre as curvas de calibração a serem utilizadas para esse tipo de método indireto, uma vez que em função da proporção de material morto no perfil do dossel o intercepto da equação de calibração varia de forma acentuada. Esse fato reflete a necessidade de calibração constante do método antes de sua utilização, além de revelar a necessidade de equações de calibração específicas para diferentes épocas do ano (Frame, 1981). Resultados semelhantes foram encontrados por Thomson (1986) quando da avaliação de diferentes métodos de estimativa de massa de forragem em pastagens consorciadas de azevém perene e trevo branco na Nova Zelândia. Esses dados corroboram, também, aqueles de Gribbs \& 
Stringer (1988), relativos à estimativa de massa de forragem em áreas de alfafa (Medicago sativa L.) através de três métodos indiretos.

O padrão de comportamento dos valores de intercepto, portanto, apontou para um padrão de agrupamento dos dados originais de massa de forragem e altura correspondente do prato ascendente que pôde ser associado às estações do ano, ou seja, primavera (outubro a dezembro), verão (janeiro a março), outono (abril a junho) e inverno (julho e agosto), muito embora não tenham sido observadas diferenças marcantes entre os meses de inverno e início e meio de primavera. Esta orientação de agrupamento foi utilizada na análise de regressão final que resultou nas equações de calibração do método do prato ascendente para o período experimental.

\subsubsection{Método da régua}

De forma semelhante ao método do prato ascendente, houve diferença entre cultivares $(\mathrm{P}<0,05)$ para os valores médios de intercepto e de coeficiente angular das equações de calibração geradas inicialmente para os doze meses do período experimental (Tabela 6).

Tabela 6. Valores médios do intercepto ( $\mathrm{kg} \mathrm{MS} / \mathrm{ha})$ e do coeficiente angular (Kg $\mathrm{MS} / \mathrm{cm}$ ) das equações de calibração do método da régua para os cultivares de Cynodon spp. durante o período experimental.

\begin{tabular}{ccc}
\hline Cultivar & Intercepto & Coeficiente Angular \\
\hline Florakirk & $2336^{\mathrm{a}}$ & $198,3^{\mathrm{b}}$ \\
Tifton 85 & $1874^{\mathrm{ab}}$ & $265,4^{\mathrm{a}}$ \\
Coastcross & $1544^{\mathrm{b}}$ & $197,6^{\mathrm{b}}$ \\
EPM $^{*}$ & 147,8 & 8,70 \\
\hline
\end{tabular}

${ }^{*}$ EPM $=$ erro padrão da média

Médias na mesma coluna seguidas da mesma letra não diferem entre si $(\mathrm{P}>0,05)$ 
Os valores de intercepto foram semelhantes entre os cultivares, a única diferença tendo sido observada entre Florakirk e Coastcross, sendo o valor mais alto encontrado para o cultivar Florakirk. Contudo, um padrão diferente de resposta foi observado com relação aos valores de coeficiente angular, com Tifton 85 apresentando valor superior e diferente daqueles de Florakirk e Coastcross (Tabela 6). Assim como para o método do prato ascendente, este padrão de comportamento dos parâmetros das curvas de calibração (intercepto e coeficiente angular) geradas indica que a geração de uma curva de calibração única para os três cultivares não seria recomendável, uma vez que se tal generalização fosse feita certamente a precisão e acurácia da equação gerada seriam seriamente comprometidos, assim como a sua relevância para fins de utilização como ferramenta de monitoramento e planejamento do manejo do pastejo. Esses resultados corroboram aqueles de Oliveira et al. (2000) e Carnevalli \& Da Silva (2000).

Pelo fato dos dois métodos indiretos estudados, prato ascendente e régua, serem baseados no mesmo princípio, as mesmas ponderações feitas sobre variações em estrutura dos pastos formados pelos diferentes cultivares são pertinentes para as diferenças observadas na Tabela 6 , ratificando o fato de que apesar da grande semelhança entre cultivares, suas diferenças morfológicas e estruturais individuais, assim com seu padrão de variação ao longo do ano, condenam a prática de estratégias únicas e generalizadas de manejo do corte e do pastejo para esses cultivares (Da Silva et al., 1998; Fagundes et al., 1999; Carnevalli, 1999; Carvalho, 2000; Sbrissia, 2000 e Pinto, 2000).

Quanto a variação dos valores médios de intercepto (Tabela 7) e coeficiente angular (Tabela 8) ao longo do período experimental, foram observadas diferenças entre os meses do ano $(\mathrm{P}<0,05)$, exceção feita aos valores de coeficiente angular para Florakirk. 
Tabela 7. Valores médios de intercepto ( $\mathrm{kg} \mathrm{MS} / \mathrm{ha}$ ) das curvas de calibração da régua para os cultivares Florakirk, Tifton 85 e Coastcross durante o período experimental.

\begin{tabular}{cccc}
\hline Meses & Florakirk & Tifton 85 & Coastcross \\
\hline Junho/98 & $3792^{\mathrm{a}}$ & $2887^{\mathrm{ab}}$ & $2063^{\mathrm{abc}}$ \\
Julho/98 & $2431^{\mathrm{bc}}$ & $2512^{\mathrm{abc}}$ & $1885^{\mathrm{abc}}$ \\
Agosto/98 & $2269^{\mathrm{bc}}$ & $1892^{\mathrm{bcd}}$ & $1701^{\mathrm{bc}}$ \\
Setembro/98 & $2656^{\mathrm{ab}}$ & $2235^{\mathrm{bcd}}$ & $1518^{\mathrm{cdef}}$ \\
Outubro/98 & $2803^{\mathrm{ab}}$ & $1522^{\mathrm{cde}}$ & $2848^{\mathrm{ab}}$ \\
Novembro/98 & $3719^{\mathrm{a}}$ & $3607^{\mathrm{a}}$ & $3042^{\mathrm{a}}$ \\
Dezembro/98 & $2734^{\mathrm{ab}}$ & $2504^{\mathrm{abc}}$ & $1670^{\mathrm{cd}}$ \\
Janeiro/99 & $1354^{\mathrm{cd}}$ & $1210^{\mathrm{de}}$ & $512^{\mathrm{def}}$ \\
Fevereiro/99 & $906^{\mathrm{d}}$ & $766^{\mathrm{de}}$ & $233^{\mathrm{f}}$ \\
Março/99 & $1315^{\mathrm{cd}}$ & $689^{\mathrm{e}}$ & $1134^{\mathrm{cdef}}$ \\
Abril/99 & $1891^{\mathrm{bcd}}$ & $892^{\mathrm{de}}$ & $397^{\mathrm{ef}}$ \\
Maio/99 & $2165^{\mathrm{bc}}$ & $1769^{\mathrm{bcde}}$ & $1527^{\mathrm{cde}}$ \\
EPM $^{*}$ & 426,0 & 426,0 & 426,0 \\
\hline
\end{tabular}

$E P M=$ erro padrão da média

Médias na mesma coluna seguidas da mesma letra não diferem entre si $(\mathrm{P}>0,05)$ 
Tabela 8. Valores médios de coeficiente angular $(\mathrm{kg} \mathrm{MS} / \mathrm{cm})$ das curvas de calibração da régua para os cultivares Florakirk, Tifton 85 e Coastcross durante o período experimental.

\begin{tabular}{cccc}
\hline Meses & Florakirk & Tifton 85 & Coastcross \\
\hline Junho/98 & $190,4^{\mathrm{a}}$ & $248,6^{\mathrm{ab}}$ & $245,5^{\mathrm{a}}$ \\
Julho/98 & $158,5^{\mathrm{a}}$ & $227,2^{\mathrm{ab}}$ & $145,1^{\mathrm{b}}$ \\
Agosto/98 & $205,4^{\mathrm{a}}$ & $271,2^{\mathrm{ab}}$ & $193,2^{\mathrm{ab}}$ \\
Setembro/98 & $158,7^{\mathrm{a}}$ & $262,1^{\mathrm{ab}}$ & $182,7^{\mathrm{ab}}$ \\
Outubro/98 & $177,3^{\mathrm{a}}$ & $321,0^{\mathrm{a}}$ & $62,3^{\mathrm{b}}$ \\
Novembro/98 & $199,8^{\mathrm{a}}$ & $216,1^{\mathrm{b}}$ & $186,8^{\mathrm{ab}}$ \\
Dezembro/98 & $206,3^{\mathrm{a}}$ & $268,9^{\mathrm{ab}}$ & $205,3^{\mathrm{ab}}$ \\
Janeiro/99 & $212,9^{\mathrm{a}}$ & $236,2^{\mathrm{ab}}$ & $229,1^{\mathrm{ab}}$ \\
Fevereiro/99 & $231,5^{\mathrm{a}}$ & $244,2^{\mathrm{ab}}$ & $246,1^{\mathrm{a}}$ \\
Março/99 & $231,9^{\mathrm{a}}$ & $302,0^{\mathrm{ab}}$ & $188,0^{\mathrm{ab}}$ \\
Abril/99 & $184,6^{\mathrm{a}}$ & $293,4^{\mathrm{ab}}$ & $248,1^{\mathrm{a}}$ \\
Maio/99 & $221,5^{\mathrm{a}}$ & $294,3^{\mathrm{ab}}$ & $236,7^{\mathrm{ab}}$ \\
EPM $^{*}$ & 34,72 & 34,72 & 34,72 \\
\hline
\end{tabular}

$\mathrm{EPM}=$ erro padrão da média

Médias na mesma coluna seguidas da mesma letra não diferem entre si $(\mathrm{P}>0,05)$

Como discutido anteriormente para o método indireto do prato ascendente, as variações observadas nos valores de intercepto e coeficiente angular durante o período experimental foram consequência da variação em estrutura dos pastos ao longo do ano. Essas variações foram descritas de forma detalhada por Fagundes (1999), Carnevalli (1999), Carvalho (2000), Sbrissia (2000) e Pinto (2000) e estiveram altamente correlacionadas com as variações observadas em precipitação e temperatura média do ambiente, características das diferentes estações do ano. Além disso, variações em estrutura do pasto podem ser devidas não exclusivamente a diferenças morfológicas e estruturais das plantas forrageiras mas, também, a padrões diferenciados de partição de fotoassimilados para a biossíntese de novos tecidos, ou seja, crescimento. Pinto (2000), 
estudando os mesmos cultivares em experimento concomitante na área experimental, descreveu variações nos padrões de acúmulo de tecido proveniente de hastes relativamente a lâminas foliares para os diferentes cultivares e diferentes épocas do ano, fato este que também deve ter contribuído para o efeito estacional de comportamento dos valores de intercepto e de coeficiente angular das equações de calibração geradas. A associação dessa diferença em padrão de deposição de tecidos (crescimento) e na densidade de área foliar resultante dos dados de Fagundes (1999) e Carnevalli (1999) permite compreender a razão pela qual o coeficiente angular para Tifton 85 diferiu daqueles de Florakirk e Coastcross no caso do método da régua. Por se tratar de um método que avalia a altura não comprida do pasto, respeitando o arranjo e a orientação original das partes morfológicas das plantas no dossel, o cultivar com maior densidade de área foliar e com maiores taxas de acúmulo de forragem tende a gerar valores de coeficiente angular, ou seja, incrementos em massa de forragem com incrementos correspondentes em altura, mais elevados. No caso do prato ascendente, que mede a altura comprimida do pasto (altura x densidade "bulk" da forragem), a variação nos valores de coeficiente angular foram mais modestas, provavelmente pelo efeito de compressão gerado pelo peso do prato ascendente utilizado. Esse resultado está de acordo com o experimento de Gonçalez et al. (1990), que também trabalhou com plantas do gênero Cynodon (capim bermuda).

Com relação aos coeficientes angulares, houve uma variação muito discreta ao longo do ano para Tifton 85 e Coastcross, com os valores observados para Florakirk comportando-se de maneira bastante uniforme. Excetuando-se os valores de coeficiente angular do mês de junho para o cultivar Coastcross, mês de intenso florescimento (Carvalho, 2000) e alteração em estrutura do pasto por alteração de estádio fisiológico das plantas (Carnevalli, 1999), e do mês de novembro para o cultivar Tifton 85, mês em que ocorreu a menor quantidade de precipitação dos últimos 40 anos, os valores de coeficiente angular dos demais meses do ano também mostraram-se bastante semelhantes, como para Florakirk. Assim, conforme observado e discutido para o método do prato ascendente, o efeito de época do ano foi maior sobre o intercepto das curvas de calibração, com pequena influência relativa sobre os valores de coeficiente angular dos pastos formados pelos diferentes cultivares de Cynodon spp., revelando, 
mais uma vez, a necessidade de calibrações frequentes do método para representar as variações em condições climáticas, estratégia de desfolha e manejo dos pastos em diferentes localidades e épocas do ano (Frame, 1981; Aiken \& Bransby, 1992; Santillan at al., 1979 e Bransby et al., 1997).

Novamente, o padrão de comportamento dos valores de intercepto apontou para um padrão de agrupamento dos dados originais de massa de forragem e altura correspondente da régua relacionado com as estações do ano, ou seja, primavera (outubro a dezembro), verão (janeiro a março), outono (abril a junho) e inverno (julho e agosto), padrão este que foi utilizado para a análise de regressão final que resultou nas equações de calibração do método para o período experimental.

\subsection{Equações de Calibração dos Métodos Indiretos de Estimativa de Massa de Forragem - Prato Ascendente e Régua}

A análise preliminar dos dados para os dois métodos estudados (item 4.1) revelou um padrão de agrupamento dos pares de dados (altura e massa de forragem) comum para os dois métodos, segundo o qual cada cultivar deveria ter uma equação de calibração própria, equação essa que deveria ser calculada com base em épocas distintas do ano correspondentes a primavera (englobando os dados dos meses de outubro, novembro e dezembro), verão (janeiro, fevereiro e março), outono (abril, maio e junho) e inverno (julho, agosto e setembro). Com base nesse padrão de agrupamento foram realizadas as análises finais de regressão entre massa de forragem e a altura de pasto correspondente, gerando-se as equações de calibração dos métodos estudados.

As equações de calibração geradas para os métodos indiretos do prato ascendente e da régua são apresentadas nas Tabelas 9 e 10. As equações geradas refletem, para cada cultivar, as variações em estrutura dos pastos ocorridas nas diferentes estações do ano (Frame, 1981; Aiken \& Bransby, 1992; Santillan at al., 1979 e Bransby et al., 1997). A maior diferença aparente foi referente aos valores de intercepto, os quais tiveram uma alta associação com a proporção de material morto no perfil dos pastos (Fagundes, 1999; Carnevalli, 1999). Durante o período de verão, época do ano de temperaturas mais elevadas e maior ocorrência de chuvas, os valores de intercepto foram mais baixos, 
diferentemente das demais épocas do ano. Adicionalmente, para uma altura hipotética zero $(\mathrm{H})$, a massa de forragem resultante, para qualquer um dos métodos, seria bastante diferente e superior a zero. Tal situação é comum na maioria de sistemas biológicos, especialmente pastagens. Um valor nulo de altura não está normalmente associado com a ausência de forragem e não há, necessariamente, um aumento proporcional em massa de forragem com o aumento de uma unidade no valor de altura do pasto, razão pela qual coeficientes de determinação inferiores a 1,0 são geralmente encontrados (Thomson, 1986). Quanto ao coeficiente angular, independentemente do método estudado, Tifton 85 apresentou os valores mais altos nas quatro estações do ano, provavelmente consequência de sua maior densidade "bulk" de forragem (Carnevalli, 1999), maior IAF e menor coeficiente de extinção luminosa (Fagundes, 1999) relativamente a Florakirk e Coastcross. Essas diferenças morfológicas e de arquitetura dos cultivares de Cynodon spp. estudados também explicam os valores relativamente mais baixos de intercepto e de coeficiente angular para o método do prato ascendente quando comparados àqueles do método da régua. O prato ascendente baseia-se na leitura de uma altura dita comprimida, compressão essa função do peso do prato utilizado e que, portanto, gera uma estimativa de massa de forragem baseada num parâmetro híbrido entre altura e densidade "bulk" do pasto (Frame, 1981; Manneteje, 2000 e Gomes et al., 2000). Com as características acima descritas seria de se esperar que o grau de compressão da forragem pelo prato fosse menor para Tifton 85 , como de fato ocorreu. No caso do método da régua, a altura medida é sem compressão alguma e, assim, o cultivar com maior densidade "bulk" e folhas mais eretas (menor coeficiente de extinção luminosa) deveria resultar nos maiores incrementos de massa de forragem com o aumento em altura do pasto, fato observado, também, para Tifton 85 . 
Tabela 9. Equações de calibração para a estimativa de massa de forragem em pastos formados por cultivares de Cynodon spp. através do método do prato ascendente.

\begin{tabular}{cccccc}
\hline Cultivar & \multicolumn{1}{c}{ Equação ${ }^{*}$} & $\mathrm{R}^{2}$ & $\mathrm{CV}(\%)^{* *}$ & $\mathrm{EPR}^{* * *}$ & Prob $>\mathrm{F}$ \\
\hline Florakirk & $\mathrm{M}=3570+120 \mathrm{H}$ & 0,54 & 28 & 1576 & 0,0001 \\
Tifton 85 & $\mathrm{M}=3055+165 \mathrm{H}$ & 0,73 & 23 & 1445 & 0,0001 \\
Coastcross & $\mathrm{M}=2480+125 \mathrm{H}$ & 0,49 & 33 & 1532 & 0,0001 \\
& & $\underline{\text { Verão: }}$ & & & \\
Florakirk & $\mathrm{M}=1660+145 \mathrm{H}$ & 0,80 & 24 & 1025 & 0,0001 \\
Tifton 85 & $\mathrm{M}=1515+160 \mathrm{H}$ & 0,77 & 26 & 1174 & 0,0001 \\
Coastcross & $\mathrm{M}=995+155 \mathrm{H}$ & 0,86 & 21 & 745 & 0,0001 \\
& & $\underline{\text { Outono: }}$ & & \\
Florakirk & $\mathrm{M}=2760+135 \mathrm{H}$ & 0,52 & 31 & 1529 & 0,0001 \\
Tifton 85 & $\mathrm{M}=2125+175 \mathrm{H}$ & 0,65 & 30 & 1557 & 0,0001 \\
Coastcross & $\mathrm{M}=1885+150 \mathrm{H}$ & 0,63 & 31 & 1334 & 0,0001 \\
& & $\underline{\text { Inverno: }}$ & & \\
Florakirk & $\mathrm{M}=2790+115 \mathrm{H}$ & 0,68 & 24 & 1214 & 0,0001 \\
Tifton 85 & $\mathrm{M}=2855+145 \mathrm{H}$ & 0,73 & 23 & 1275 & 0,0001 \\
Coastcross & $\mathrm{M}=1965+135 \mathrm{H}$ & 0,68 & 27 & 1192 & 0,0001 \\
\hline
\end{tabular}

${ }^{*} \mathrm{M}=$ massa de forragem em $\mathrm{Kg} \mathrm{MS} / \mathrm{ha}$ e $\mathrm{h}=$ altura do pasto em centímetros

${ }^{* *} \mathrm{CV}=$ coeficiente de variação

${ }^{* *} \mathrm{EPR}$ = erro padrão da regressão (Raiz quadrada do quadrado médio do resíduo da regressão) 
Tabela 10. Equações de calibração para a estimativa de massa de forragem em pastos formados por cultivares de Cynodon spp. através do método da régua.

\begin{tabular}{|c|c|c|c|c|c|}
\hline Cultivar & Equação ${ }^{*}$ & $\mathrm{R}^{2}$ & $\mathrm{CV}(\%)^{* *}$ & $\mathrm{EPR}^{* * *}$ & Prob $>F$ \\
\hline & \multicolumn{5}{|c|}{ Primavera: } \\
\hline Florakirk & $\mathrm{M}=3080+195 \mathrm{H}$ & 0,60 & 26 & 1471 & 0,0001 \\
\hline Tifton 85 & $M=2600+265 \mathrm{H}$ & 0,72 & 23 & 1462 & 0,0001 \\
\hline \multirow[t]{2}{*}{ Coastcross } & $\mathrm{M}=2590+150 \mathrm{H}$ & 0,40 & 36 & 1675 & 0,0001 \\
\hline & \multicolumn{5}{|c|}{ Verão: } \\
\hline Florakirk & $M=1260+220 \mathrm{H}$ & 0,77 & 25 & 1091 & 0,0001 \\
\hline Tifton 85 & $M=895+265 \mathrm{H}$ & 0,81 & 24 & 1058 & 0,0001 \\
\hline \multirow[t]{2}{*}{ Coastcross } & $M=710+215 H$ & 0,85 & 22 & 773 & 0,0001 \\
\hline & \multicolumn{5}{|c|}{ Outono: } \\
\hline Florakirk & $M=2360+205 \mathrm{H}$ & 0,60 & 28 & 1389 & 0,0001 \\
\hline Tifton 85 & $\mathrm{M}=1695+280 \mathrm{H}$ & 0,71 & 27 & 1412 & 0,0001 \\
\hline \multirow[t]{2}{*}{ Coastcross } & $M=1520+210 H$ & 0,64 & 30 & 1303 & 0,0001 \\
\hline & \multicolumn{5}{|c|}{$\underline{\text { Inverno: }}$} \\
\hline Florakirk & $\mathrm{M}=2720+155 \mathrm{H}$ & 0,61 & 26 & 1329 & 0,0001 \\
\hline Tifton 85 & $\mathrm{M}=2470+230 \mathrm{H}$ & 0,69 & 25 & 1355 & 0,0001 \\
\hline Coastcross & $\mathrm{M}=1755+170 \mathrm{H}$ & 0,64 & 29 & 1265 & 0,0001 \\
\hline
\end{tabular}

O nível de significância de todas as equações geradas (Prob $>$ F) foi bastante elevado (Tabelas 9 e 10). No entanto, os valores de coeficiente de determinação obtidos foram relativamente baixos $(0,49$ a 0,86 e 0,40 a 0,85 para os métodos do prato ascendente e da régua, respectivamente), indicando que uma proporção significativa da variação em massa de forragem não pôde ser devidamente explicada pela variação em altura correspondente (14 a $51 \%$ e 15 a $60 \%$ para o prato ascendente e régua, respectivamente), caracterizando a limitação dos modelos matemáticos gerados para a predição de massa de forragem nas circunstâncias deste experimento. Geralmente 
valores de coeficiente de determinação inferiores a 0,75 são considerados baixos e pouco satisfatórios (Thomsom, 1986). Os coeficientes de variação (CV) das equações podem ser considerados relativamente baixos dada a natureza dos dados e o tamanho da área de amostragem. No entanto, os valores de erro padrão da regressão (EPR), medida de dispersão mais interessante para fins de avaliação de curvas de calibração dessa natureza e que representa a distância média entre o valor real de massa observado e a reta estabelecida pelo modelo, foram elevados, variando de 745 a 1576 e de 773 a $1675 \mathrm{Kg}$ $\mathrm{MS} /$ ha para os métodos do prato e da régua, respectivamente. Isso implicaria em um erro médio de estimativa de massa de forragem de cerca de 1100 a $1200 \mathrm{Kg} \mathrm{MS} / \mathrm{ha}$ para o prato e para a régua, respectivamente, números esses suficientemente grandes para causar distorções significativas em exercícios de planejamento estratégico de uso e alocação da forragem disponível em situações de campo, podendo comprometer o nível de precisão de avaliações de massa de forragem em condições experimentais. Resultados semelhantes foram obtidos por Sanderson et al. (2001), onde constatou-se que subestimativas geradas pelos métodos indiretos estudados resultaram em prejuízos para um sistema de produção hipotético avaliado, prejuízos esses caracterizados por menores quantidades de feno e silagem sendo confeccionados, mais forragem sendo pastejada e mais forragem sendo comprada em relação ao cenário ideal de trabalho. O contrário ocorreu nas situações onde foram geradas super estimativas de massa de forragem.

Segundo Thomson (1986), valores superiores a 400-500 kg MS/ha são considerados altos e podem comprometer estimativas de massa de forragem em pastagens de azevém perene. Como forma de reduzir o EPR das curvas de calibração geradas, certamente a medida mais eficaz seria o aumento do número de pontos de amostragem por unidade experimental, de forma a permitir que o banco de dados gerado incorporasse uma maior proporção da variabilidade existente nas unidades experimentais e permitisse um melhor ajuste dos modelos matemáticos, o que resultaria em curvas de calibração mais robustas e precisas.

A análise conjunta das Tabelas 9 e 10 revela que nenhum dos métodos mostrouse superior ao outro como ferramenta para predição da massa de forragem a partir de uma medida da altura do dossel do pasto, uma vez que as equações de calibração de ambos os métodos apresentaram valores de erro padrão da regressão relativamente altos 
e com coeficientes de determinação considerados apenas modestos. Sanderson et al. (2001), avaliando métodos indiretos de estimativa de massa de forragem, também obtiveram baixa precisão e exatidão quando as estimativas geradas foram comparadas com os valores determinados de forma direta através de corte da forragem. Contudo, o método do prato ascendente, desde que devidamente calibrado, permite uma maior velocidade de trabalho e economia de tempo e mão-de-obra que o método da régua, permitindo que uma maior proporção da área total de cada unidade experimental ou de amostragem seja amostrada reduzindo, consequentemente, o erro de amostragem para uma quantidade semelhante (ou menor) de esforço e tempo (Santillan et al., 1979; Frame, 1981 e Lopes et al., 2000). O mesmo raciocínio é válido para a comparação entre ambos os métodos indiretos e o direto, baseado no corte e pesagem de todas as amostras de forragem, revelando a praticidade e o potencial de uso dessa técnica de avaliação para o monitoramento de campos experimentais e pastagens em condições de fazenda. 


\section{CONCLUSÕES}

Os resultados obtidos neste experimento permitiram que as seguintes conclusões fossem formuladas:

$\checkmark$ As equações de calibração para ambos os métodos estudados devem ser específicas para cada cultivar;

$\checkmark$ Variações em estrutura do dossel forrageiro ao longo do ano implicaram na necessidade de calibração frequente dos métodos;

$\checkmark$ A intensidade de amostragem para fins de calibração do método precisa ser aumentada para que as equações geradas sejam mais robustas e precisas;

$\checkmark$ Os dois métodos estudados não diferiram em eficácia de predição. 


\section{REFERÊNCIAS BIBLIOGRÁFICAS}

AIKEN, G. E.; BRANSBY, D.I. Observer variability for disk meter measurements of forage mass. Agronomy Journal, v.84, p.603-605, 1992.

BARNETT, V. Simple random sampling. In: BARNETT, V. Elements of sampling theory. London: Enghish Universities Press, 1974. p. 22-48.

BRANSBY, D.I.; MATCHES, A.G.; KRAUSE, G.F. Disk meter for rapid estimation of herbage yield in grazing trials. Agronomy Journal, v. 69, p.393-396, 1977.

BRASIL.Ministério da Agricultura. Serviço Nacional de Pesquisa Agronômica. Comissão de Solos. Levantamento de reconhecimento dos solos do estado de São Paulo. Rio de janeiro, 1960. 634p. (Boletim, 12).

CAMARGO, A.C. Produção de leite à pasto In: SIMPÓSIO SOBRE MANEJO DE PASTAGEM - PRODUÇÃO DE BOVINOS À PASTO, 13, Piracicaba, 1996. Anais. Piracicaba: FEALQ, 1997. p.221-241. 
CAMPBELL N.A.; ARNOLD, G.W. The visual assessment of pasture yield. Australian Journal of Experimental Agriculture and Animal Husbandry, v.13, p.263-267, 1973.

CARNEVALLI, R.A. Desempenho de ovinos e respostas de pastagens de Cynodon spp. submetidas a regimes de desfolha sob lotação continua. Piracicaba,1999. 90p. Dissertação (Mestrado) - Escola Superior de Agricultura Luiz de Queiroz, Universidade de São Paulo.

CARNEVALLI, R.A.; Da SILVA, S.C. Validação de técnicas experimentais para avaliação de características agronômicas e ecológicas de pastegns de cynodon dactylon cv. "Coast-Cross-1". Scientia Agricola, v.56, p.489-499, 1999.

CARNEVALLI, R.A.; Da SILVA, S.C. Avaliação de características agronômicas e ecológicas de Cynodon dactylon para validação de técnicas para ensaios de pastejo (compact disc). In: REUNIAO ANUAL DA SOCIEDADE BRASILEIRA DE ZOOTECNIA, 37., Viçosa, 2000. Anais. Viçosa: SBZ, 2000.

CARVALHO, C.A.B. Padrões demográficos de perfilhamento e acúmulo de forragem em pastagens de Cynodon spp. manejadas em quatro intensidades de pastejo. Piracicaba, 2000. 80p. Dissertação (Mestrado) - Escola Superior de Agricultura Luiz de Queiroz, Universidade de São Paulo. 
CÓSER, A.C.; MARTINS, C.E.; ALVIM, M.J.; TEIXEIRA, F.V. Altura da planta e cobertura do solo como estimadores da produção de massa de forragem em pastagens de capim-elefante. Revista da Sociedade Brasileira de Zootecnia, v. 27, n.4, p.676-680, 1998.

DA SILVA, S.C. Produção sem mágica.Produtor Parmalat, v.1, n. 9, p. 10-12, nov. 1997.

DA SILVA, S.C.; PEDREIRA, C.G.S. Fatores condicionantes e predisponentes da produção animal a pasto. In: SIMPÓSIO SOBRE MANEJO DE PASTAGEM, 13., Piracicaba, 1996. Anais. Piracicaba: FEALQ, 1996. p.317-327.

DA SILVA, S.C.; PEDREIRA, C.G.S. Princípios de ecologia aplicados ao manejo da pastagem. In: SIMPÓSIO SOBRE ECOSSISTEMAS DE PASTAGENS, 3., Jaboticabal, 1997. Anais. Jaboticabal:FUNEP, 1997.p.1-62.

DA SILVA, S.C.; SBRISSIA, A.F. A planta forrageira no sistema de produção. In: SIMPÓSIO SOBRE MANEJO DE PASTAGEM - A PLANTA FORRAGEIRA NO SISTEMA DE PRODUÇÃO, 17., Piracicaba, 2000. Anais. Piracicaba:FEALQ, 2000. p.3-21.

DA SILVA, S.C.; PASSANEZI, M.M.; CARNEVALLI, R.A.; PEDREIRA, C.G.S.; FAGUNDES, J.L. Bases para o estabelecimento do manejo de Cynodon spp. para pastejo e conservação. In: SIMPÓSIO SOBRE O MANEJO DA PASTAGEM, 15. Piracicaba, 1998.Anais. FEALQ, Piracicaba: 1998. p.129-150. 
DOBASHI, A.F.; PENATI, M.A.; BARIONI, L. G.; CORSI, M.; JACINTHO,G.C. Avaliação de três métodos indiretos para a determinação de massa de forragem em pastagem rotacionada de Panicum maximum cv.Tanzânia em diferentes níveis de resíduo sob irrigação (compact disc). In: REUNIAO ANUAL DA SOCIEDADE BRASILEIRA DE ZOOTECNIA, 38., Piracicaba, 2001. Anais. Piracicaba: SBZ, 2001.

ESCOLA SUPERIOR DE AGRICULTURA “LUIZ DE QUEIROZ”. Departamento de Ciências Exatas. Médias mensais e total de chuvas. http://www.ce.esalq.usp.br/ (16 nov. 2001).

ESTRADA, C.L.H.; NASCIMENTO JUNIOR, D.; REGAZZI, A.J. Efeito do número e tamanho do quadrado nas estimativas pelo Botanal da composição e disponibilidade de matéria seca de pastagens cultivadas. Revista Sociedade Brasileira de Zootecnia. v. 20, n.50, p.483-493.1991.

FAGUNDES, J.L. Efeito de intensidades de pastejo sobre o índice de área foliar, interceptação luminosa e acúmulo de forragem em pastagens de Cynodon spp. Piracicaba,1999. 59p. Dissertação (Mestrado) - Escola Superior de Agricultura Luiz de Queiroz, Universidade de São Paulo.

FAGUNDES, J.L.; DA SILVA, S.C.; PEDREIRA, C.G.S; SBRISSIA, A.F.; CARNEVALLI, S.A.; CARVALHO, C.A.B.; PINTO, L.F.M. Índice de área foliar, interceptação luminosa e acúmulo de forragem em pastagens de Cynodon spp. sob diferentes intensidades de pastejo. Scientia Agricola, v.56, n.4, p.1141-1150, 1999. 
FAGUNDES,J.L.; DA SILVA, S.C.; PEDREIRA, C.G.S; SBRISSIA, A.F.; CARNEVALli, S.A.; CARVALHO, C.A.B.; PINTO, L.F.M. Índice de área foliar, coeficiente de extinção luminosa e acúmulo de forragem em pastagens de Cynodon spp. sob lotação continua. Pesquisa Agropecuária Brasileira, v.36, n.1. p.187-195, 2001.

FNP CONSULTORIA \& COMÉRCIO. ANUALPEC 2000: anuário da pecuária brasileira, São Paulo, 2000. 392 p.

FRAME, J. Herbage mass. In: HODGSON, J.; BAKER, R.D.; DAVIES, A.; LAIDLAW, A.S.; LEAVER, J.D. (Ed.) Sward measurement handbook. Berkshire: Bristh Grassland Society, 1981. cap.3, p.39-67.

GARCIA FILHO, A. Capacitância. www.facens.br/site/alunos/disciplinas/eletromag/site/teoria/ aula9/ (16 nov.2001).

GOMES, K.E.; MARASCHIN, G.E.; RIBOLDI, J. Efeitos de ofertas de forragem, diferimentos e adubações sobre a dinâmica de uma pastagem natural. I.Acumulação e matéria seca (compact disc). In: REUNIAO ANUAL DA SOCIEDADE BRASILEIRA DE ZOOTECNIA, 37., Viçosa, 2000. Anais. Viçosa: SBZ, 2000.

GONZALEZ, M.A.; HUSSEY M. A.; CONRAD, B. E. Plant heigh, disk, and capacitance meters used to estimate bermudagrass herbage mass. Agronomy Journal, v.82, p.861-864, 1990. 
GRIGGS, T.C.; STRINGER, W.C. Prediction of alfalfa herbage mass using sward height, ground cover, and disk technique. Agronomy Journal, v. 80, p. 204-208, 1988 .

GUZMAN, G.A.B.; NASCIMENTO JUNIOR, D.; REGAZZI, A.J.; OBEID, J.A.; QUEIROZ, A.C. Estudo do tamanho e forma ideal da unidade amostral na avaliação da disponibilidade de matéria seca em pastagens. I- Método da máxima curvatura do coeficiente de variação. Revista da Sociedade Brasileira de Zootecnia, v. 21, n.3, p.396-405, 1992.

HAYDOCK, K.P.; SHAW, N.H. The comparative yield method for estimating dry matter yield of pasture. Australian Journal of Experimental Agriculture and Animal Husbandry, v.15, p.663-670, 1975.

HODGSON, J. Grazing management: science practice. Essex: Longman Scientific \& Technical, 1990. 203 p.

LOPES, R.S.; FONSECA, D.M.; COSER, A.C.; NASCIMENTO JUNIOR, D.; MARTINS, C.E.; OBEID, J.C. Avaliação de métodos para estimação da disponibilidade de forragem em pastagem de capim-elefante (compact disc). In: REUNIAO ANUAL DA SOCIEDADE BRASILEIRA DE ZOOTECNIA, 37., Viçosa, 2000. Anais. Viçosa: SBZ, 2000. 
MANNETJE'T L. Measuring biomass of grassland vegetation. In: MANNETJE'T, L.; JONES , R.M. (Ed.) Field and laboratory methods for grassland and animal production research. Wallingford: CAB International, 2000. cap.7, p. 151-177.

MANNETJE'T, L. Measuring quantity of grassland vegetation. In: MANNETJE'T, L. (Ed.) Measurement of grassland vegetation and animal production. Berkshire: CAB International, 1987. cap.4, p.63-95.

MARASHIN, E.G. Produção de carne à pasto In: SIMPÓSIO SOBRE MANEJO DE PASTAGEM - PRODUÇÃO DE BOVINOS À PASTO, 13., Piracicaba, SP, 1996. Anais. Piracicaba:FEALQ, 1997. p.243-273.

MITIDIERI, J. Manual de gramíneas e leguminosas para os pastos tropicais. São Paulo: Nobel, 1983. 198p.

NABINGER, C. Princípios da exploração intensiva de pastagem. In: SIMPÓSIO SOBRE MANEJO DE PASTAGEM - PRODUÇÃO DE BOVINOS À PASTO, 13., Piracicaba, 1996. Anais. Piracicaba: FEALQ, 1997. p.15-95.

OLIVEIRA, D.E.; MEDEIROS, S.R.; AROEIRA, L.J.M.; BARIONI, L.G.; LANNA, D.P.D. Estimating herbage mass in stargrass using sward surface height and the plate meter. In: INTERNATIONAL GRASSLAND CONGRESS, 19., Águas de São Pedro, 2001. Proceedings. Piracicaba:FEALQ, 2001. p. 1055-1056. 
OMETO, J.C. Registros e estimativas dos parâmetros meteorológicos da região de Piracicaba, S.P. Piracicaba: FEALQ,1989.76p.

O'ROURKE, P.K., McCOSKER, T.H., TEITZEL, J.K., STEPHENSON, H.P., WILSON, R.J. Application and appraisal of a visual estimation technique for composition and yield sampling of legume pastures in the wet tropics of northeastern Australia. Australian Journal of Experimental Agriculture and Animal Husbandry, v.24, n.127, p.535-542, 1984.

ROLIM, F.A. Estacionalidade de produção de forrageiras. In: PEIXOTO, AM.; MOURA, J.C.; FARIA, V.P. (Ed.) Pastagens: fundamentos da exploração racional, Piracicaba: FEALQ, 1994. v. 2, p.533-566.

SAS. INSTITUTE. SAS user's guide: release. 6.03, Cary, 1998. 1028p.

SANDERSON, M.A.; ROTZ, C.A.; FULTZ, S.W.; RAYBURN, E.B. Estimating forage mass witch a commercial capacitance meter, rising plate meter and pasture ruler. Agronomy Journal, v.93, p. 1281-1286, 2001.

SANTILLAN, R. A.; OCUMPAUGH, W.R.; MOTT. G.O. Estimating forage yield with a Disk Meter. Agronomy Journal. v. 71, p.71-74, 1979.

SBRISSIA, A.F. Compensação e tamanho/densidade populacional de perfilhos em pastagens de Cynodon spp. Piracicaba, 2000. 70p. Dissertação (Mestrado) - Escola Superior de Agricultura Luiz de Queiroz, Universidade de São Paulo. 
SHAW, N.H.; MANNETJE'T, L.; JONES, R.M. Pasture Measurements In: MANNETJE'T, L. (Ed.) Measurement of grassland vegetation and animal production. Berkshire: CAB. International,1987. cap,10, p.63-95.

THOMSON, N.A.. Techniques available for assessing pasture. In: MASSEY UNIVERSITY. Dairy farming annual. New Zeland, 1986. p. 113-121. 